\title{
Depressive, anxiety and hypomanic symptoms in schizophrenia may be driven by tryptophan catabolite (TRYCAT) patterning of IgA and IgM responses directed to TRYCATs
}

\author{
Buranee Kanchanatawan $^{\mathrm{a}}$, Sunee Sirivichayakul ${ }^{\mathrm{b}}$, André F. Carvalho ${ }^{\mathrm{c}}$, George Anderson ${ }^{\mathrm{d}}$, \\ Piotr Galecki ${ }^{\mathrm{e}}$, Michael Maes ${ }^{\mathrm{a}, \mathrm{f}, \mathrm{g}, \mathrm{h}, \mathrm{i}, *}$ \\ a Department of Psychiatry, Faculty of Medicine, Chulalongkorn University, Bangkok, Thailand \\ b Faculty of Medicine, Chulalongkorn University, Bangkok, Thailand \\ ${ }^{\mathrm{c}}$ Department of Clinical Medicine and Translational Psychiatry Research Group, Faculty of Medicine, Federal University of Ceará, Fortaleza, CE, Brazil \\ d CRC Scotland \& London, Eccleston Square, London, UK \\ e Department of Adult Psychiatry, Medical University of Lodz, Poland \\ ${ }^{\mathrm{f}}$ Department of Psychiatry, Medical University of Plovdiv, Plovdiv, Bulgaria \\ ${ }^{g}$ Department of Psychiatry, Faculty of Medicine, State University of Londrina, Londrina, Brazil \\ ${ }^{\mathrm{h}}$ Revitalis, Waalre, The Netherlands \\ i IMPACT Strategic Research Center, Deakin University, Geelong, Australia
}

\section{A R T I C L E I N F O}

\section{Keywords:}

Schizophrenia

Depression

Anxiety

Immune

Inflammation

Indoleamine 2,3-dioxygenase

Kynurenine

\begin{abstract}
A B S T R A C T
The aim of this study was to delineate the associations between the tryptophan catabolite (TRYCAT) pathway and affective symptoms in schizophrenia. Towards this end we measured immunoglobulin (Ig)A and IgM responses to relatively noxious TRYCATs, namely quinolinic (QA), xanthurenic (XA), picolinic (PA) acid and 3-OHkynurenine (3HK), and generally protective TRYCATs, namely anthranilic (AA) and kynurenic (KA) acid in 80 patients with schizophrenia and 40 healthy controls. The Hamilton Rating Scale for Depression (HDRS) and anxiety (HAMA), Young Mania Rating Scale (YMRS) as well as the Positive and Negative Symptoms Scale of Schizophrenia (PANSS) were measured.

Depression, anxiety and hypomanic as well as negative and positive symptoms were associated with increased IgA responses to PA. Increased IgA responses to XA were associated with anxiety, hypomanic and negative symptoms. Moreover, depressive, anxiety, hypomanic and negative symptoms were characterized by increased IgA responses to the noxious (XA + 3HK + QA + PA)/protective (AA + KA) TRYCAT ratio. All symptom dimensions were associated with increased IgM responses to QA, while depressive, anxiety, positive and negative symptoms were accompanied by lowered IgM responses to 3HK. Hypomanic symptoms were additionally accompanied by lowered IgM responses to AA, and negative symptoms by increased IgM responses to KA.

In conclusion, both shared and distinct alterations in the activity of the TRYCAT pathway, as well as its regulatory factors and consequences, may underpin affective and classical psychotic symptoms of schizophrenia. Increased mucosa-generated production of noxious TRYCATs, especially PA, and specific changes in IgMmediated regulatory activities may be associated with the different symptom dimensions of schizophrenia.
\end{abstract}

\section{Introduction}

Schizophrenia is a complex psychiatric disorder, which is classically characterized by different symptom dimensions, including negative (e.g. anhedonia, social inhibition, alogia, flattened affect, loss of interest and anhedonia), positive (e.g. hallucinations, delusions, hostile and aggressive behaviors and disorganized thinking), neurocognitive (e.g. disorders in executive functions, sustained attention, and speed of processing) and affective symptoms (Andreasen and Olsen, 1982; Emsley et al., 1999; Lieberman et al., 1991; Mellor, 1991; Lindenmayer et al., 1995; Van den Oord et al., 2006; Kim et al., 2012). Many patients with schizophrenia experience affective symptoms, including depressive and anxiety symptoms, which may be secondary to positive and negative symptoms of schizophrenia (Emsley et al., 1999; Kirschner et al., 2016) and/or part of an early developmental etiology (Anderson et al., 2013). Previous work established that depression and anxiety

\footnotetext{
* Corresponding author at: IMPACT Strategic Research Center, Barwon Health, Deakin University, Geelong, Victoria, Australia.

E-mail address: dr.michaelmaes@chula.md (M. Maes).
} 
symptoms aggregate with negative symptoms and neurocognitive deficits, including dysfunctions in visual memory, executive functions, social cognition and attention (Kanchanatawan et al., 2017c).

A wide array of risk factors may contribute to the neurodevelopmental pathophysiology of schizophrenia, including neuro-immune activators, such as viral and bacterial infections, as well as perinatal and psychosocial stressors (Smith and Maes, 1995; Davis et al., 2014, 2016). As well as immune activation, other factors may play a role in the pathophysiology of schizophrenia, including dopaminergic mechanisms, glutamatergic $N$-methyl D-aspartate receptor (NMDAr) activity and a wide array of epigenetic processes, as well as oxidative and nitrosative stress (O \& NS) (Smith and Maes, 1995; Davis et al., 2014, 2016). Firstepisode, acute and chronic phases of schizophrenia are commonly accompanied by an enhanced immune-inflammatory activity, including macrophagic M1 activation, coupled to alterations in T helper (Th)1, Th2 and regulatory T cells (Maes et al., 1994, 1995; Noto et al., 2015a, 2016; Goldsmith et al., 2016).

M1- and Th1-related cytokines, as well as O\&NS, may stimulate indoleamine 2,3-dioxygenase (IDO) which drives tryptophan to the production of tryptophan catabolites (TRYCATs), thereby depriving tryptophan as a necessary precursor for serotonin and melatonin synthesis, with consequences for mitochondrial functioning (Anderson and Maes, 2016, 2017). Likewise, stress and the stress hormone, cortisol, can increase tryptophan 2,3-dioxygenease (TDO), which also increases the kynurenine/tryptophan ratio and a number of neuroregulatory TRYCATs, including xanthurenic acid (XA), picolinic acid (PA), quinolinic acid (QA), 3-OH-kynurenine (3HK), anthranilic acid (AA) and kynurenic acid (KA) (Maes et al., 2011b; Kanchanatawan et al., 2017a). Levels of some brain TRYCATs, including QA, following systemic inflammation are in part derived from TRYCATs in the blood, including circulating QA, 3HK and especially kynurenine (Kita et al., 2002). These findings indicate that peripheral TRYCATs may reflect or otherwise influence central neuro-immune mechanisms, with a wide array of possible consequences, including neurotoxic or neuroprotective, pro-inflammatory or anti-inflammatory and oxidative or anti-oxidant properties (Maes et al., 2011b; Kanchanatawan et al., 2017a, 2017b).

Enhanced TRYCAT pathway activity may be evident in schizophrenia, as indicated by lowered tryptophan concentrations and increased concentrations of TRYCATs, including kynurenine, KA, AA and QA, in plasma, cerebrospinal fluid (CSF) or brain tissues (Lee et al., 2011; Barry et al., 2009; Krause et al., 2013; Linderholm et al., 2012; Schwarcz et al., 2001; Miller et al., 2004; Schwieler et al., 2015). Another study has indicated a decrease in XA in subgroups of schizophrenia patients (Fazio et al., 2015). Using a new assay of the TRYCAT pathway that measures plasma immunoglobulin (Ig)A and IgM responses directed against TRYCATs, it was shown that schizophrenia is accompanied by increased IgA responses to $3 \mathrm{HK}$ and PA and lowered IgA responses to QA, while deficit schizophrenia was specifically accompanied by increased IgA responses to all noxious TRYCATS, namely $\mathrm{QA}, \mathrm{PA}, \mathrm{XA}$ and $3 \mathrm{HK}$, and lowered self-regulatory IgM-mediated immune responses directed to the same noxious TRYCATs (Kanchanatawan et al., 2017a, 2017b). Moreover, negative symptoms of schizophrenia were significantly associated with increased IgA responses and lowered IgM responses to noxious TRYCATs (Kanchanatawan et al., 2017a, 2017b). Thus, the patterning of IgA (indicating TRYCAT pathway activation) and IgM (indicating natural, self-regulation of the TRYCAT pathway) responses directed against TRYCATs may contribute to the emergence of psychopathological dimensions of schizophrenia, including negative symptoms (Kanchanatawan et al., 2017a, 2017b).

Affective symptoms, including depression, anxiety and hypomania are accompanied by TRYCAT pathway activation, which was proposed to be linked to altered affective processing in the amygdala (Anderson, 2011), supported by data showing stress-induced increases in amygdala QA in preclinical models (Laugeray et al., 2011). Major depressive disorder and inflammation-induced depression may be accompanied by lower peripheral levels of tryptophan and increased levels of TRYCATs (Maes et al., 1993, 2011b; Bonaccorso et al., 2000, 2002; Anderson et al., 2014). Bay-Richter et al. (2014) found that in depression, lowered KA was associated with severity of illness. Steiner et al. (2012) found that increased microglial QA is associated with severe depression. In adolescents with melancholic depression the kynurenine/tryptophan ratio is elevated (Gabbay et al., 2010). More detailed studies, however, indicate that TRYCAT pathway activity is more closely associated with different psychopathological domains of depression, including anxiety or physio-somatic symptoms (formerly known as psychosomatic symptoms, including fatigue, pain, gastro-intestinal symptoms, somatization) (Hoes, 1979; Maes et al., 2011a; Maes and Rief, 2012; Anderson et al., 2014; Roomruangwong et al., 2017a, 2017b). Moreover, no significant changes in IgA responses to TRYCATs could be detected in perinatal depression, while these IgA responses were associated with physio-somatic symptoms at the end of term and a lifetime history of premenstrual syndrome, but not major depression (Roomruangwong et al., 2017a, 2017b). Anxiety in the early puerperium is significantly associated with lowered levels of tryptophan and increased kynurenine levels (Maes et al., 2002). Evidence also suggests that anxiety could be significantly linked to the induction of the TRYCAT pathway, as evidenced by lipopolysaccharide (LPS)-induced anxiety-like behaviors, which are mediated by IDO induction (Salazar et al., 2012). In addition, mood dysregulation in the context of bipolar disorder may be associated with alterations in TRYCAT and melatonergic pathways (Anderson et al., 2016), including an association of mania with increased CSF KA levels (Olsson et al., 2012). Notwithstanding evidence indicating that TRYCAT pathway activation may contribute to the pathophysiology of affective disorders, no studies to date have examined the IgA and IgM responses to TRYCATs in relation to depressive, anxiety and manic symptoms in individuals with schizophrenia.

Thus, the current study aimed to investigate IgA and IgM responses to noxious (XA, PA, 3HK, QA) and more protective (AA and KA) TRYCATs, in relation to affective symptoms in patients with schizophrenia.

\section{Subjects and methods}

\subsection{Subjects}

This is a correlational, cross-sectional study, which recruited Thai individuals aged 18-65 years of both sexes. Consecutive outpatients with deficit and nondeficit schizophrenia in a compensated - stabilized state of illness were recruited at the Department of Psychiatry, Faculty of Medicine, Chulalongkorn University, Bangkok, Thailand. Participants were 80 outpatients with schizophrenia, 40 with non-deficit schizophrenia and 40 with primary deficit schizophrenia defined according to The Schedule for the Deficit Syndrome (Kirkpatrick et al., 1989) all from the same catchment area (Bangkok, Thailand). Deficit/ nondeficit schizophrenia was the primary recruitment criterion, while DSM-IV-TR or DSM-5 (first versus multiple episodes) diagnoses were registered. Healthy controls $(n=40)$ were recruited by word of mouth. They were apparently healthy normal individuals recruited from the same catchment population.

Diagnoses were made using the diagnostic criteria for schizophrenia of the DSM-IV-TR employing the validated Thai version of the Mini-International Neuropsychiatric Interview (M.I.N.I.) (Kittirathanapaiboon and Khamwongpin, 2005). Both patients and controls were interviewed with the M.I.N.I. Controls were excluded to participate if a lifetime or current axis I mental disorder, including schizophrenia, or a family history of schizophrenia was evident. We excluded schizophrenia individuals with a lifetime diagnosis of axis-I disorders (DSM-IV-TR) other than schizophrenia, including schizoaffective disorder, unipolar depression, bipolar disorder, anxiety 
disorders such as panic disorder, post-traumatic stress disorder, obsessive compulsive disorder, psycho-organic disorders and substance use disorders. Furthermore, subjects treated with immunomodulatory drugs or nutritional supplements, including antioxidants and $\omega 3$ polyunsaturated fatty acids, and individuals with neurologic illness, including multiple sclerosis, Parkinson's disease, Alzheimer's disorder, and (auto)immune disorders, including rheumatoid arthritis, inflammatory bowel disease, chronic obstructive pulmonary disease, diabetes and psoriasis were excluded. Some patients were taking psychopharmacological drugs, including haloperidol $(n=11)$, fluphenazine $(n=10)$, clozapine $(n=10)$, risperidone $(n=34)$, perphenazine $(n=21)$, antidepressants $(n=30)$, anxiolytics and hypnotics $(n=30)$ and mood stabilizers $(n=21)$. All participants provided written informed consent prior to participation in this study. The study was conducted according to the Thai and international ethics and privacy laws. The procedures of these studies were approved by the Institutional Review Board of the Faculty of Medicine, Chulalongkorn University, Bangkok, Thailand, which is in compliance with the International Guideline for Human Research protection, as required by the Declaration of Helsinki, The Belmont Report, CIOMS Guideline and International Conference on Harmonization in Good Clinical Practice (ICH-GCP).

\subsection{Methods}

A clinical interview (BK, a senior psychiatrist) was conducted the same day blood samplings were drawn. A semi-structured interview was performed to collect all demographic and clinical data. The following instruments were administered: the Positive and Negative Syndrome Scale (PANSS) (Kay et al., 1986), Young Mania Rating Scale (YMRS) (Young et al., 1978), Hamilton Depression (HDRS, Hamilton, 1960) and Anxiety Rating Scales (HAMA, Hamilton, 1959), as well as the validated Thai version of the Mini-International Neuropsychiatric Interview (M.I.N.I.) (Kittirathanapaiboon and Khamwongpin, 2005). For this study, we used the sums of the positive (PANSS +) and negative (PANSS - ) symptoms of the PANSS. We also used the sums of different HDRS and HAMA items: a) HDRSd, an index of "pure" depressive symptoms: sum of item 1 (depressed mood) + item 2 (feelings of guilt) + item 3 (suicide); b) HDRSps, an index of physio-somatic symptoms: sum of HDRS item 11 (anxiety somatic) + item 12 (somatic symptoms, gastrointestinal) + item 13 (somatic symptoms, general) + item 14 (genital symptoms) + item 15 (hypochondriasis); c) HAMAa, an index of "pure" anxiety symptoms HAMAa: sum of items 1 (anxious mood) + item 2 (tension) + item 3 (fears) + item 14 (anxious behavior); and HAMAps, an index of physio-somatic-anxiety symptoms: sum of HAMA items 8 (somatic sensory) + item 9 (cardiovascular symptoms) + item 10 (respiratory symptoms) + item 11 (gastrointestinal symptoms) + item 12 (genitourinary symptoms) + item 13 (autonomic symptoms). We made the diagnosis of tobacco use disorder (TUD) using DSM-IV-TR criteria and we used the Fagerstrom Nicotine Dependence Scale to check severity of nicotine dependence (Heatherton et al., 1991). Body weight and height were assessed the same day and we computed body mass index (BMI) as weight ( $\mathrm{kg}$ ) divided by height (in meters) squared.

On the same day as the clinical interview, blood was sampled at 8.00 a.m. for the assays of plasma TRYCATs. Plasma was stored at $-80{ }^{\circ} \mathrm{C}$ until thawed for assay. Syntheses of TRYCAT conjugates and ELISA assays were employed to measure immunoglobulin (Ig)M and IgA levels directed against TRYCATs (Roomruangwong et al., 2017a, 2017b; Duleu et al., 2010; Kanchanatawan et al., 2017a, 2017b). As detailed previously, the conjugates were synthesized by linking picolinic acid (PA), 3-OH-kynurenine (3HK), xanthurenic acid (XA), quinolinic acid (QA), kynurenic acid (KA) and anthranilic acid (AA) to BSA. We measured optical densities at $450 \mathrm{~nm}$ using Varioskan Flash (Thermo Scientific). All measurements were assayed in duplicate, using the same batch of antibodies, run by the same technician (SS, a Ph.D. in immunology), who was blind to the clinical ratings. All analytical intraassays CV values were $<7 \%$. The optical density scores were expressed as z scores (Roomruangwong et al., 2017b; Duleu et al., 2010).

\subsection{Statistics}

We employed analyses of contingency tables ( $\mathrm{X}^{2}$-tests) to assess associations among categories and analyses of variance (ANOVAs), or the non-parametric Kruskal-Wallis test, to check differences in continuous or ordinal variables between study groups. Protected least significant differences were used to check differences among diagnostic groups. Multivariate general linear model (GLM) analyses were employed to ascertain the multivariate effects of independent variables, including TRYCATs, on dependent variables, including HDRS, HAMA, YMRS, PANSS - and PANSS + while adjusting for putative background variables, including age, sex, education. When significant multivariate effects are observed, tests for between-subject effects are used to assess the effects of the significant independent on dependent variables. We used parameter estimates to ascertain the impact and sign of the association. The patient sample was divided into two relevant groups with respect to affective symptoms. We computed $\mathrm{z}$ unit weighted composite scores for severity of affective symptoms as the sum of the $\mathrm{z}$ values of the HDRS (zHDRS) + zHAMA + zYMRS and consequently used the median-split method to obtain two groups of equal size, namely patients with increased affective symptoms (that is zHDRS + zHAMA + zYMRS $>$ median value) versus those with less affective symptoms (zHDRS + zHAMA + zYMRS $<$ median value). The rationale is that in our sample of schizophrenia patients and using principal component (PC) analysis, all three scores were highly loaded on a first $\mathrm{PC}$, indicating that in schizophrenia there is one general dimension of affective symptoms forming a spectrum of intertwined depressive, anxiety and hypomanic symptoms (results not shown). The participants were subsequently allocated to three study groups, namely healthy controls and schizophrenia patients, with lower versus higher affective scores. Automatic stepwise regression was used to determine the most significant predictors using IgA and IgM responses directed to TRYCATs as well as age, sex and education as explanatory variables and the rating scale scores as dependent variables. Results of multivariate and univariate regression analyses were checked for multicollinearity employing tolerance and variance inflation factor. Entered in the statistical analyses were IgA and IgM responses to the 6 TRYCATs separately. We have additionally calculated $\mathrm{z}$ unit weighted composite scores for the ratios between noxious (NOX) TRYCATs with increased cytotoxic, neurotoxic, excitotoxic, and pro-inflammatory and oxidative potential (PA, XA, QA, 3HK) versus more protective (PRO) TRYCATs (AA and KA) (Kanchanatawan et al., 2017a, 2017b). IgA and IgM responses to the NOX/PRO TRYCAT ratio were computed as: a) IgA responses to NOX/PRO (IgA NOX/PRO) $=\mathrm{z}$ value of IgA response to QA (zQA) $+\mathrm{zPA}+\mathrm{zXA}+\mathrm{z} 3 \mathrm{HK}-\mathrm{zAA}-\mathrm{zKA}$, and $\mathrm{b})$ IgM responses to NOX/ $\mathrm{PRO}(\mathrm{IgM} \mathrm{NOX} / \mathrm{PRO})=\mathrm{z}$ value of $\mathrm{IgM}$ response to QA (zQA) $+\mathrm{zPA}+\mathrm{zXA}+\mathrm{z} 3 \mathrm{HK}-\mathrm{zAA}-\mathrm{zKA}$. We have also calculated the $\Delta$ differences between the IgA (indicating activation) and IgM (indicating regulation) responses ( $\Delta$ zIgA - zIgM) directed to all TRYCATs. For example, $\triangle \mathrm{PA}$ was computed as $\mathrm{z}$ IgA directed to $\mathrm{PA}-\mathrm{z}$ IgM value directed to PA (Kanchanatawan et al., 2017b). Finally, we also used the $\Delta$ NOX/PRO ratio computed as z IgA NOX/PRO - zIgM NOX/PRO. All tests were two-tailed and $\alpha=0.05$ indicated a statistically significant effect. All statistical analyses were performed using IBM SPSS Windows version 22 .

\section{Results}

\subsection{Descriptive statistics}

Table 1 shows the socio-demographic, clinical and TRYCATs data in the three study groups, i.e. healthy controls and schizophrenic patients 
Table 1

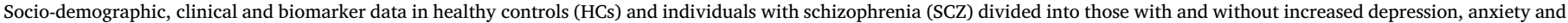
hypomanic symptoms ( \pm DAHss).

\begin{tabular}{|c|c|c|c|c|c|c|}
\hline Variables & $\begin{array}{l}\mathrm{HC}^{\mathrm{a}} \\
n=40\end{array}$ & $\begin{array}{l}\text { SCZ - DAHss } \\
n=40\end{array}$ & $\begin{array}{l}\mathrm{SCZ}+\mathrm{DAHss}^{\mathrm{a}} \\
n=40\end{array}$ & $\mathrm{~F} / \mathrm{X}^{2}$ & $\mathrm{df}$ & $\mathrm{p}$ \\
\hline Age (years) & $37.4(12.8)$ & $41.3(11.0)$ & $40.9(11.2)$ & 1.37 & $2 / 117$ & 0.259 \\
\hline $\operatorname{Sex}(M / F)$ & $10 / 30^{\mathrm{a}}$ & $24 / 16^{\mathrm{a}}$ & $19 / 21$ & 10.21 & 2 & 0.006 \\
\hline Education (years) & $14.3(4.9)$ & $12.6(3.9)$ & $12.1(4.4)$ & 2.71 & $2 / 117$ & 0.070 \\
\hline TUD (N/Y) & $38 / 2$ & $35 / 5$ & $40 / 0$ & - & - & - \\
\hline BMI $\left(\mathrm{kg} / \mathrm{m}^{2}\right)$ & $24.0(4.3)$ & $24.6(4.8)$ & $24.4(5.5)$ & 0.13 & $2 / 122$ & 0.877 \\
\hline Single/married & $26 / 14^{\mathrm{a}}$ & $31 / 7$ & $36 / 4^{\mathrm{a}}$ & 7.74 & 2 & 0.021 \\
\hline No work/work & $4 / 36^{\mathrm{a}}$ & $18 / 22^{\mathrm{a}}$ & $28 / 12^{\mathrm{a}}$ & 29.90 & 2 & $<0.001$ \\
\hline DSM V (single/multiple) & - & $6 / 23$ & $4 / 24$ & 0.40 & 1 & 0.525 \\
\hline DSM IVTR (P/D/R) & - & $25 / 5 / 4$ & $25 / 5 / 4$ & 0.00 & 2 & 1.000 \\
\hline HDRS & $0.6(2.0)^{\mathrm{a}}$ & $3.9(3.3)^{\mathrm{a}}$ & $11.0(5.2)^{\mathrm{a}}$ & 79.50 & $2 / 117$ & $<0.001$ \\
\hline HAMA & $2.6(5.4)^{\mathrm{a}}$ & $5.1(3.4)^{\mathrm{a}}$ & $17.7(8.8)^{\mathrm{a}}$ & 67.07 & $2 / 117$ & $<0.001$ \\
\hline YMRS & $0.1(0.5)^{\mathrm{a}}$ & $0.8(1.2)^{\mathrm{a}}$ & $3.8(4.2)^{\mathrm{a}}$ & 22.54 & $2 / 117$ & $<0.001$ \\
\hline PANSS + & $7.0(0.0)^{\mathrm{a}}$ & $10.8(4.6)^{\mathrm{a}}$ & $18.1(8.2)^{\mathrm{a}}$ & 42.90 & $2 / 116$ & $<0.001$ \\
\hline PANSS - & $7.0(0.0)^{\mathrm{a}}$ & $15.7(9.1)^{\mathrm{a}}$ & $22.9(10.5)^{\mathrm{a}}$ & 39.48 & $2 / 116$ & $<0.001$ \\
\hline IgA PA (z score) & $-0.35(1.03)^{\mathrm{a}}$ & $+0.02(0.86)$ & $+0.33(1.01)^{\mathrm{a}}$ & 5.01 & $2 / 117$ & 0.008 \\
\hline IgA 3HK (z score) & $-0.39(0.85)^{\mathrm{a}}$ & $+0.08(0.97)^{\mathrm{a}}$ & $+0.31(1.06)^{\mathrm{a}}$ & 5.14 & $2 / 117$ & 0.005 \\
\hline IgA XA (z score) & $-0.22(1.03)$ & $-0.04(0.85)$ & $+0.26(1.07)$ & 2.45 & $2 / 117$ & 0.091 \\
\hline IgA QA (z score) & $+0.03(1.15)$ & $-0.13(0.78)$ & $+0.09(1.04)$ & 0.52 & $2 / 117$ & 0.599 \\
\hline IgA KA (z score) & $-0.05(1.13)$ & $-0.09(0.89)$ & $+0.14(0.97)$ & 0.57 & $2 / 117$ & 0.570 \\
\hline IgA AA (z score) & $+0.08(1.12)^{\mathrm{a}}$ & $-0.13(0.81)$ & $+0.05(1.06)$ & 0.51 & $2 / 117$ & 0.601 \\
\hline IgA NOX/PRO (z score) & $-0.96(1.83)^{\mathrm{a}}$ & $+0.15(1.88)^{\mathrm{a}}$ & $+0.81(2.06)^{\mathrm{a}}$ & 8.65 & $2 / 117$ & $<0.001$ \\
\hline IgM PA & $+0.05(075)$ & $-0.06(0.94)$ & $+0.01(1.26)$ & 0.13 & $2 / 117$ & 0.876 \\
\hline IgM 3HK & $+0.18(0.77)$ & $-0.12(0.94)$ & $-0.06(1.23)$ & 1.01 & $2 / 117$ & 0.369 \\
\hline IgM XA & $+0.08(0.76)$ & $-0.10(0.91)$ & $+0.02(1.27)$ & 0.30 & $2 / 117$ & 0.743 \\
\hline IgM QA & $-0.01(0.66)$ & $-0.06(0.87)$ & $+0.07(1.36)$ & 0.16 & $2 / 117$ & 0.853 \\
\hline IgM KA & $+0.08(0.77)$ & $-0.08(0.92)$ & $+0.00(1.27)$ & 0.27 & $2 / 117$ & 0.767 \\
\hline IgM AA & $+0.08(0.77)$ & $-0.04(1.00)$ & $-0.32(1.20)$ & 0.17 & $2 / 117$ & 0.846 \\
\hline IgM NOX/PRO & +0.14 (1.39) & $-0.21(1.77)$ & $-0.24(1.87)$ & 0.63 & $2 / 117$ & 0.536 \\
\hline
\end{tabular}

All results are shown as mean ( $\pm \mathrm{SD}$ ); F: analyses of variance; $\mathrm{X}^{2}$ : analyses of contingency tables.

TUD: tobacco use disorder.

BMI: body mass index.

HDRS: Hamilton Depression Rating Scale.

HAMA: Hamilton Anxiety Rating Scale.

YMRS: Young Mania Rating Scale.

PANSS + : Positive and Negative Syndrome Scale, sum of the positive symptom subscale.

PANSS - : Positive and Negative Syndrome Scale, sum of the negative symptom subscale.

All IgA and IgM responses directed tryptophan catabolites (TRYCATs) are expressed as z-scores.

PA: picolinic acid, 3HK: 3-OH-kynurenne, XA: xanthurenic acid, QA: quinolinic acid, KA: kynurenic acid, AA: anthranilic acid.

NOX: noxious TRYCATS with neurotoxic, excitotoxic, inflammatory and oxidative properties, PRO: more protective TRYCATs.

NOX/PRO: $\mathrm{z}$ scores PA + 3HK + XA + QA - z scores KA + AA.

${ }^{a}$ Results of protected post-hoc tests comparing the three groups.

divided into those with higher, versus lower, zHDRS + zHAMA + zYMRS values. We found no significant differences in age, BMI, education and TUD between the three study groups. There were significant differences in the sex-ratio, ratio of single/married and ratio of no work/employed among the three groups. There were significant differences in the affective rating scales between the three groups with significant higher values in the schizophrenia patients. Furthermore, the PANSS + and PANSS - values were significantly different between the three groups and increased from healthy controls to patients with a lower zHDRS + zHAMA + zYMRS score to those with a higher zHDRS + zHAMA + zYMRS score. There were no significant differences in DSM-V and DSM-IV-TR diagnoses between the two schizophrenia subgroups. Table 1 also shows the IgA and IgM responses to the 6 TRYCATs as well as the NOX/PRO ratio. IgA responses to PA were significantly higher in patients with more affective symptoms than in controls. IgA responses to 3HK and NOX/PRO ratio were significantly higher in both schizophrenia subgroups, as compared to controls. There were no significant differences in the IgM responses between the three study samples. We did not employ p-corrections to evaluate these univariate tests as these tests, as well as the Pearson and point-biserial correlation matrices between the variables, were used to delineate the variables to be used as predictors in the ultimate multivariate regression analyses.

\subsection{Association between symptom profiles and IgA responses to TRYCATs}

Table 2 shows the results of three different multivariate GLM analyses with the HDRS, HAMA, YMRS, PANSS + and PANSS - scores as dependent variables and IgA responses to TRYCATs as explanatory variables, while adjusting for background variables. Regression \#1 shows that IgA responses to PA, 3HK, QA and AA had significant effects on the five rating scale scores after adjusting for sex and education (age was not significant in this equation). Tests for between-subjects effects showed that the HDRS score was associated with higher IgA responses to PA and 3HK but lowered IgA responses to AA. HAMA, YMRS and PANSS + scores were associated with higher IgA responses to PA. PANSS - scores were predicted by increased IgA responses to QA and PA and lowered IgA responses to AA.

Regression \#2 shows that IgA responses directed to XA had a significant effect on the five rating scales, after controlling for education and sex, which are not shown in this table as similar to regression \#1. Tests for between-subject effects showed that increased IgA responses to XA are related to HAMA, YMRS and PANSS - score. Regression \#3 shows a significant effect of IgA responses to the NOX/PRO ratio on the five rating scales, while the between-subject effects show significant univariate associations between IgA NOX/PRO responses and HDRS, HAMA, YMRS and PANSS - scores. 
Table 2

Results of multivariate GLM analysis with five clinical rating scales as dependent variables and IgA responses to tryptophan catabolites (TRYCATs) as explanatory variables.

\begin{tabular}{|c|c|c|c|c|c|c|}
\hline Type test & Dependent variables & Explanatory variables & $\mathrm{F}$ & $\mathrm{df}$ & $\mathrm{p}$ & Partial eta squared \\
\hline \multirow[t]{6}{*}{ Multivariate $\neq 1$} & HDRS, HAMA, YMRS, & IgA PA & 3.28 & $5 / 106$ & 0.009 & 0.134 \\
\hline & PANSS,+ PANSS - & IgA 3HK & 3.54 & $5 / 106$ & 0.005 & 0.143 \\
\hline & & IgA QA & 2.72 & $5 / 106$ & 0.024 & 0.114 \\
\hline & & IgA AA & 2.85 & $5 / 106$ & 0.019 & 0.118 \\
\hline & & Sex & 2.45 & $5 / 106$ & 0.039 & 0.103 \\
\hline & & Education & 2.65 & $5 / 106$ & 0.027 & 0.111 \\
\hline \multirow{14}{*}{ Between-subject effects } & HDRS & $\operatorname{IgA} \mathrm{PA}(+)$ & 11.75 & $1 / 110$ & 0.001 & 0.097 \\
\hline & & $\operatorname{IgA} 3 \mathrm{HK}(+)$ & 9.31 & $1 / 110$ & 0.003 & 0.078 \\
\hline & & IgA AA $(-)$ & 7.92 & $1 / 110$ & 0.006 & 0.067 \\
\hline & & Education & 11.97 & $1 / 110$ & 0.001 & 0.098 \\
\hline & HAMA & $\operatorname{IgA} \mathrm{PA}(+)$ & 6.33 & $1 / 110$ & 0.013 & 0.054 \\
\hline & & Education & 4.40 & $1 / 110$ & 0.038 & 0.038 \\
\hline & YMRS & $\operatorname{IgA} \mathrm{PA}(+)$ & 7.60 & $1 / 110$ & 0.007 & 0.065 \\
\hline & PANSS + & $\operatorname{IgA} P A(+)$ & 6.63 & $1 / 110$ & 0.011 & 0.057 \\
\hline & PANSS - & $\operatorname{Sex}(M>F)$ & 6.42 & $1 / 110$ & 0.013 & 0.055 \\
\hline & & $\operatorname{IgA} \mathrm{PA}(+)$ & 7.59 & $1 / 110$ & 0.007 & 0.065 \\
\hline & & $\operatorname{IgA} Q A(+)$ & 5.86 & $1 / 110$ & 0.017 & 0.051 \\
\hline & & $\operatorname{IgA} A A(-)$ & 11.21 & $1 / 110$ & 0.001 & 0.092 \\
\hline & & Education & 9.84 & $1 / 110$ & 0.002 & 0.082 \\
\hline & & Sex & 6.42 & $1 / 110$ & 0.013 & 0.055 \\
\hline \multirow[t]{2}{*}{ Multivariate $\neq 2$} & HDRS, HAMA, YMRS, & IgA XA & 3.78 & $5 / 111$ & 0.013 & 0.145 \\
\hline & PANSS,+ PANSS - & & & & 2 & \\
\hline \multirow[t]{3}{*}{ Between-subject effect } & HAMA & $\operatorname{IgAXA}(+)$ & 3.96 & $1 / 115$ & 0.049 & 0.032 \\
\hline & YMRS & $\operatorname{IgAXA}(+)$ & 6.14 & $1 / 115$ & 0.015 & 0.051 \\
\hline & PANSS - & $\operatorname{IgAXX}(+)$ & 9.23 & $1 / 115$ & 0.003 & 0.074 \\
\hline Multivariate $\neq 3$ & $\begin{array}{l}\text { HDRS, HAMA, YMRS, } \\
\text { PANSS +, PANSS - }\end{array}$ & IgA NOX/PRO & 5.42 & $5 / 111$ & $<0.001$ & 0.196 \\
\hline \multirow{4}{*}{ Between-subject effect } & HDRS & IgA NOX/PRO & 12.86 & $1 / 115$ & $<0.001$ & 0.061 \\
\hline & HAMA & IgA NOX/PRO & 8.17 & $1 / 115$ & 0.003 & 0.072 \\
\hline & YMRS & IgA NOX/PRO & 9.66 & $1 / 115$ & 0.002 & 0.077 \\
\hline & PANSS - & IgA NOX/PRO & 14.76 & $1 / 115$ & $<0.001$ & 0.114 \\
\hline
\end{tabular}

HDRS: Hamilton Depression Rating Scale; HAMA: Hamilton Anxiety Rating Scale; YMRS: Young Mania Rating Scale.

PANSS + : Positive and Negative Syndrome Scale, sum of the positive symptom subscale.

PANSS - : Positive and Negative Syndrome Scale, sum of the negative symptom subscale.

Tryptophan catabolites (TRYCATs) data are IgA responses to picolinic acid (PA), 3-OH-kynurenine (3HK), quinolinic acid (QA), anthranilic acid (AA) and xanthurenic acid (XA).

NOX: noxious TRYCATS with neurotoxic, excitotoxic, inflammatory and oxidative properties, PRO: more protective TRYCATs.

NOX/PRO: $\mathrm{z}$ scores $\mathrm{PA}+3 \mathrm{HK}+\mathrm{XA}+\mathrm{QA}-\mathrm{z}$ scores $\mathrm{KA}+\mathrm{AA}$.

\subsection{Possible effects of confounding variables}

No significant effects of age ( $\mathrm{F}=0.25, \mathrm{df}=5 / 105, p=0.938)$ or TUD ( $F=0.67, \mathrm{df}=5 / 105, p=0.647$ ) were found. Significant effects of the drug state of the patients on the 5 rating scales were evident, namely haloperidol $(n=11, \mathrm{~F}=7.92, \mathrm{df}=5 / 103, p<0.001)$, fluphenazine $(n=10, \mathrm{~F}=3.22, \mathrm{df}=5 / 103, p=0.010)$ and anxiolytics and hypnotics $(n=30, \mathrm{~F}=5.84, \mathrm{df}=5 / 103, p<0.001)$. The use of haloperidol was significantly associated with higher ratings on the YMRS and PANSS -, fluphenazine with higher PANSS + ratings and anxiolytics with higher HAMA, HDRS and PANSS - ratings, thereby indicating that patients with a more severe psychopathology were more often treated with these drugs. The effects of the TRYCATs, however, were not affected, namely IgA responses to PA ( $F=4.34$, $\mathrm{df}=5 / 103$, $p=0.001)$, 3HK $(\mathrm{F}=3.41, \mathrm{df}=5 / 103, p=0.007), \mathrm{QA}(\mathrm{F}=2.92$, $\mathrm{df}=5 / 103, p=0.017)$ and $\mathrm{AA}(\mathrm{F}=3.27, \mathrm{df}=5 / 103, p=0.009)$. No effects of other psychotropic drugs could be found, namely clozapine $(n=10, \mathrm{~F}=1.94, \mathrm{df}=5 / 102, p=0.094)$, risperidone $(n=34$, $\mathrm{F}=1.73, \mathrm{df}=5 / 102, p=0.134)$, perphenazine $(n=21, \mathrm{~F}=0.49$, $\mathrm{df}=5 / 102, p=0.784)$, antidepressants $(n=30, \mathrm{~F}=2.10, \mathrm{df}=5$ / $102, p=0.071)$ and mood stabilizers $(n=21, \mathrm{~F}=2.05, \mathrm{df}=5 / 102$, $p=0.079$ ). Moreover, there were no significant effects of the psychopharmacological drug treatment on the 6 IgA responses to TRYCATs and NOX/PRO ratio, e.g. haloperidol $(\mathrm{F}=1.75$, df $=6 / 108$, $p=0.116$ ), fluphenazine ( $\mathrm{F}=0.35$, $\mathrm{df}=6 / 108, p=0.911)$ and anxiolytics or hypnotics $(\mathrm{F}=1.31$, $\mathrm{df}=6 / 108, p=0.257$ ).

\subsection{Association between symptom profiles and IgM responses to TRYCATs}

Table 3 shows the outcome of three multivariate GLM analyses, with the five rating scales as dependent variables and the IgM responses to TRYCATs as explanatory variables, while adjusting for sex and education (age was not significant). Regression \#1 shows that IgM responses to QA and 3HK have significant effects on the 5 rating scales, while tests for between-subject effects showed that HDRS, HAMA, PANSS + and PANSS - scores are associated with increased IgM responses to QA and lowered responses to $3 \mathrm{HK}$. We again checked whether putative background variables could have any significant effect and therefore we added to regression 1 , the use of haloperidol, fluphenazine and anxiolytics or hypnotics and found no changes in impact of IgM responses directed against $\mathrm{QA}(\mathrm{F}=3.60, \mathrm{df}=5 / 106, p=0.005)$ and $3 \mathrm{HK}$ $(\mathrm{F}=3.64, \mathrm{df}=5 / 106, p=0.004)$ on the rating scale scores. Also entering age, TUD, use of clozapine, risperidone, perphenazine, antidepressants and mood stabilizers did not change the results. Also, no significant effects of the drug state of the patients on the IgM responses to QA and 3HK (as dependent variables) were evident.

Table 3 (regression \#2) shows that there were significant effects of IgM responses to $\mathrm{KA}$ and $3 \mathrm{HK}$ on the rating scale scores (with an equivalent result using the combination of 3HK and QA). Tests for between-subject effects show that IgM response directed to KA was positively associated with PANSS - score. Multivariate regression \#3 shows that IgM response to NOX/PRO ratio was significantly and inversely associated with PANSS - scores. 
Table 3

Results of multivariate GLM analysis with five clinical rating scales as dependent variables and IgM responses to tryptophan catabolites (TRYCATs) as explanatory variables.

\begin{tabular}{|c|c|c|c|c|c|c|}
\hline Type test & Dependent variables & Explanatory variables & $\mathrm{F}$ & df & $\mathrm{p}$ & Partial eta squared \\
\hline \multirow[t]{4}{*}{ Multivariate $\neq 1$} & \multirow[t]{4}{*}{ HDRS, HAMA, YMRS, PANSS +, PANSS - } & IgM QA & 3.27 & $5 / 109$ & 0.009 & 0.130 \\
\hline & & IgM 3HK & 4.87 & $5 / 109$ & $<0.001$ & 0.183 \\
\hline & & Education & 4.10 & $5 / 109$ & 0.002 & 0.158 \\
\hline & & Sex & 3.26 & $5 / 109$ & 0.009 & 0.130 \\
\hline \multirow[t]{14}{*}{ Between-subject effects } & \multirow[t]{3}{*}{ HDRS } & $\operatorname{IgM} \mathrm{QA}(+)$ & 8.46 & $1 / 113$ & 0.004 & 0.070 \\
\hline & & $\operatorname{IgM} 3 \mathrm{HK}(+)$ & 13.59 & $1 / 113$ & $<0.001$ & 0.107 \\
\hline & & Education $(-)$ & 16.11 & $1 / 113$ & $<0.001$ & 0.125 \\
\hline & \multirow[t]{3}{*}{ HAMA } & $\operatorname{IgM} \mathrm{QA}(+)$ & 6.91 & $1 / 113$ & 0.010 & 0.058 \\
\hline & & $\operatorname{IgM} 3 \mathrm{HK}(-)$ & 7.73 & $1 / 113$ & 0.006 & 0.064 \\
\hline & & Education $(-)$ & 6.66 & $1 / 113$ & 0.011 & 0.056 \\
\hline & PANSS + & $\operatorname{IgM} \mathrm{QA}(+)$ & 6.61 & $1 / 113$ & 0.011 & 0.055 \\
\hline & \multirow[t]{7}{*}{ PANSS - } & $\operatorname{IgM} 3 \mathrm{HK}(-)$ & 4.72 & $1 / 113$ & 0.032 & 0.040 \\
\hline & & Education $(-)$ & 5.35 & $1 / 113$ & 0.023 & 0.045 \\
\hline & & Sex $(M>F)$ & 12.26 & $1 / 113$ & 0.001 & 0.098 \\
\hline & & $\operatorname{IgM} \mathrm{QA}(+)$ & 15.10 & $1 / 113$ & $<0.001$ & 0.118 \\
\hline & & $\operatorname{IgM} 3 \mathrm{HK}(-)$ & 23.52 & $1 / 113$ & $<0.001$ & 0.172 \\
\hline & & Education $(-)$ & 17.41 & $1 / 113$ & $<0.001$ & 0.133 \\
\hline & & $\operatorname{Sex}(M>F)$ & 5.19 & $1 / 113$ & 0.025 & 0.044 \\
\hline \multirow[t]{2}{*}{ Multivariate $\neq 2$} & \multirow{2}{*}{ HDRS, HAMA, YMRS, PANSS +, PANSS - } & IgM 3HK & 5.15 & $5 / 109$ & $<0.001$ & 0.191 \\
\hline & & IgM KA & 3.29 & $5 / 109$ & 0.008 & 0.131 \\
\hline \multirow[t]{3}{*}{ Between-subject effects } & HDRS & $\operatorname{IgM} 3 \mathrm{HK}(-)$ & 5.68 & $1 / 113$ & 0.019 & 0.048 \\
\hline & \multirow[t]{2}{*}{ PANSS - } & $\operatorname{IgM} 3 \mathrm{HK}(-)$ & 21.83 & $1 / 113$ & $<0.001$ & 0.162 \\
\hline & & $\operatorname{IgM} \mathrm{KA}(+)$ & 14.71 & $1 / 113$ & $<0.001$ & 0.115 \\
\hline Multivariate $\neq 3$ & HDRS, HAMA, YMRS, PANSS +, PANSS - & IgM NOX/PRO & 3.66 & $5 / 110$ & 0.004 & 0.143 \\
\hline Between-subject effects & PANSS - & IgM NOX/PRO (-) & 5.56 & $1 / 114$ & 0.020 & 0.046 \\
\hline
\end{tabular}

HDRS: Hamilton Depression Rating Scale.

HAMA: Hamilton Anxiety Rating Scale.

YMRS: Young Mania Rating Scale.

PANSS + : Positive and Negative Syndrome Scale, sum of the positive symptom subscale.

PANSS -: Positive and Negative Syndrome Scale, sum of the negative symptom subscale.

TRYCATs data are IgM responses to quinolinic acid (QA), 3-OH-kynurenine (3HK) and kynurenic acid (KA).

NOX: noxious TRYCATS with neurotoxic, excitotoxic, inflammatory and oxidative properties, PRO: more protective TRYCATs.

NOX/PRO: z scores PA + 3HK + XA + QA - z scores KA + AA.

\subsection{Association between symptom profiles and $\triangle$ IgA-IgM responses to TRYCATs}

Table 4 shows the associations between the five rating scales and the $\Delta \operatorname{IgA}-\operatorname{IgM}$ responses. The best prediction of the rating scales was obtained for the regression on $\triangle 3 \mathrm{HK}$ and $\triangle \mathrm{QA}$ responses (while adjusting for sex and education). Tests for between-subject effects showed that $\triangle 3 \mathrm{HK}$ was significantly and positively associated with HDRS, HAMA, and PANSS - scores, while $\triangle \mathrm{QA}$ was significantly and inversely associated with HDRS, HAMA and PANSS + scores. Regressions \#2 and \#3 show that also $\triangle \mathrm{PA}$ and $\triangle \mathrm{XA}$ are significantly associated with the five rating scales when entered alone (due to multicollinearity these TRYCATs do not show cumulative effects). $\triangle$ PA was significantly and positively associated with HDRS, YMRS and PANSS - scores, while $\triangle \mathrm{XA}$ is significantly associated with the HDRS and PANSS - score. Multivariate regression \#4 shows that the $\triangle$ NOX/PRO responses were significantly and positively associated with the HDRS, HAMA and PANSS - scores.

\subsection{Association between HDRS and HAMA subscales and IgA/IgM responses to TRYCATs}

Table 5 shows the associations between the subscales HDRSd, HDRSps, HAMAa and HAMAps and YMRS, PANSS + and PANSS - as dependent variables and the IgA and IgM responses to TRYCATs as explanatory variables. The aim of regression \#1 was to delineate the most significant IgA and IgM predictors of the seven rating scales, and the aim of regression \#2 was to delineate the most important $\Delta$ predictors of the seven rating scales. Regression \#1 shows that the IgA responses to PA (positively) and AA (inversely) were associated with the seven rating scale scores, whereas IgM responses to the NOX/PRO ratio were significantly and inversely associated with the PANSS score. Introducing age, TUD and the drug state variables did not change the significance levels of these TRYCAT variables. Regression \#2 shows that $\triangle 3 \mathrm{HK}$ and $\triangle \mathrm{QA}$ values were significantly associated with the seven rating scale scores. $\triangle 3 \mathrm{HK}$ values were significantly and positively associated with HDRSd, HDRSps, HAMAa, HAMAps and PANSS - rating scale scores. $\triangle \mathrm{QA}$ values were significantly and inversely associated with HDRSps and PANSS + scores.

\subsection{Results of univariate regression analyses}

In order to further explore the possible associations between the distinct psychopathological dimensions and TRYCATs, an automatic stepwise regression analyses was performed with the rating scales as dependent variables and the IgA/IgM responses to TRYCATs, age, sex, education, TUD and the medication as independent variables. Table 6 shows that $34.7 \%$ of the variance in HDRS was explained by the regression on IgA to $3 \mathrm{HK}$ and IgA to PA (both positively), IgA to AA and IgM to $3 \mathrm{HK}$ (both negatively) and education. HDRSd was not significantly predicted by any of the TRYCAT values. HDRSps on the other hand was predicted by IgA to $3 \mathrm{HK}$ and IgA to PA (both positively) and IgA to AA (inversely). $13.6 \%$ of the variance in HAMA was explained by the regression on IgA to $\mathrm{PA}$ (positive), IgA to $\mathrm{AA}$ (negative) and education. HAMAa was predicted by IgA to PA (positive) and IgA to QA (negative), while HAMAps was predicted by IgA responses to XA (positive) and to AA (inversely). $31.3 \%$ of the variance in YMRS was explained by a combination of IgA and IgM data. Furthermore, PANSS + and PANSS - rating scores were differently predicted by IgA and IgM data, with IgM responses to QA (positively) and 3HK (negatively) being 
Table 4

Results of multivariate GLM analysis with five clinical rating scales as dependent variables and IgA - IgM responses to tryptophan catabolites (TRYCATs) as explanatory variables.

\begin{tabular}{|c|c|c|c|c|c|c|}
\hline Type test & Dependent variables & Explanatory variables & $\mathrm{F}$ & df & $\mathrm{p}$ & Partial eta squared \\
\hline \multirow[t]{4}{*}{ Multivariate $\neq 1$} & \multirow[t]{4}{*}{ HDRS, HAMA, YMRS, PANSS + , PANSS - } & $\Delta 3 \mathrm{HK}$ & 5.93 & $5 / 109$ & $<0.001$ & 0.214 \\
\hline & & $\Delta \mathrm{QA}$ & 4.54 & $5 / 109$ & 0.001 & 0.174 \\
\hline & & Education & 4.19 & $5 / 109$ & 0.002 & 0.161 \\
\hline & & Sex & 2.75 & $5 / 109$ & 0.022 & 0.112 \\
\hline \multirow[t]{11}{*}{ Between-subject effects } & \multirow[t]{3}{*}{ HDRS } & $\Delta 3 \mathrm{HK}(+)$ & 26.51 & $1 / 113$ & $<0.001$ & 0.190 \\
\hline & & $\Delta \mathrm{QA}(-)$ & 11.74 & $1 / 113$ & 0.001 & 0.094 \\
\hline & & Education $(-)$ & 19.59 & $1 / 113$ & $<0.001$ & 0.148 \\
\hline & \multirow[t]{3}{*}{ HAMA } & $\Delta 3 \mathrm{HK}(+)$ & 9.19 & $1 / 113$ & 0.003 & 0.075 \\
\hline & & $\Delta \mathrm{QA}(-)$ & 5.10 & $1 / 113$ & 0.026 & 0.043 \\
\hline & & Education $(-)$ & 7.56 & $1 / 113$ & 0.007 & 0.063 \\
\hline & PANSS + & $\Delta \mathrm{QA}(-)$ & 4.71 & $1 / 113$ & 0.032 & 0.040 \\
\hline & \multirow[t]{4}{*}{ PANSS - } & Education $(-)$ & 5.72 & $1 / 113$ & 0.018 & 0.048 \\
\hline & & $\operatorname{Sex}(M>F)$ & 9.30 & $1 / 113$ & 0.003 & 0.076 \\
\hline & & $\Delta 3 \mathrm{HK}(+)$ & 5.52 & $1 / 113$ & 0.021 & 0.047 \\
\hline & & Education $(-)$ & 14.47 & $1 / 113$ & $<0.001$ & 0.113 \\
\hline Multivariate $\neq 2$ & HDRS, HAMA, YMRS, PANSS +, PANSS - & $\Delta \mathrm{PA}$ & 5.53 & $5 / 110$ & $<0.001$ & 0.202 \\
\hline \multirow[t]{3}{*}{ Between-subject effects } & HDRS & $\Delta \mathrm{PA}(+)$ & 6.61 & $1 / 114$ & 0.011 & 0.055 \\
\hline & YMRS & $\Delta \mathrm{PA}(+)$ & 4.20 & $1 / 114$ & 0.043 & 0.036 \\
\hline & PANSS - & $\Delta \mathrm{PA}(+)$ & 11.85 & $1 / 114$ & 0.001 & 0.094 \\
\hline Multivariate $\neq 3$ & HDRS, HAMA, YMRS, PANSS +, PANSS - & $\Delta \mathrm{XA}(+)$ & 5.12 & $5 / 110$ & $<0.001$ & 0.189 \\
\hline \multirow[t]{2}{*}{ Between-subject effects } & HDRS & $\Delta \mathrm{XA}(+)$ & 7.8112 .79 & $1 / 114$ & 0.006 & 0.064 \\
\hline & PANSS - & $\Delta \mathrm{XA}(+)$ & & $1 / 114$ & 0.001 & 0.101 \\
\hline Multivariate $\neq 4$ & HDRS, HAMA, YMRS, PANSS +, PANSS - & $\Delta \mathrm{NOX} / \mathrm{PRO}$ & 7.08 & $5 / 110$ & $<0.001$ & 0.243 \\
\hline \multirow[t]{3}{*}{ Between-subject effects } & HDRS & $\triangle \mathrm{NOX} / \mathrm{PRO}(+)$ & 15.10 & $1 / 114$ & $<0.001$ & 0.117 \\
\hline & HAMA & $\triangle \mathrm{NOX} / \mathrm{PRO}(+)$ & 5.12 & $1 / 114$ & 0.026 & 0.043 \\
\hline & PANSS - & $\triangle \mathrm{NOX} / \mathrm{PRO}(+)$ & 20.28 & $1 / 114$ & $<0.001$ & 0.151 \\
\hline
\end{tabular}

HDRS: Hamilton Depression Rating Scale.

HAMA: Hamilton Anxiety Rating Scale.

YMRS: Young Mania Rating Scale.

PANSS + : Positive and Negative Syndrome Scale, sum of the positive symptom subscale.

PANSS - : Positive and Negative Syndrome Scale, sum of the negative symptom subscale.

TRYCATs data are $\triangle \mathrm{IgA}$ - IgM responses to quinolinic acid (QA), 3-OH-kynurenine (3HK), picolinic acid (PA), xanthurenic acid (XA) and NOX/PRO ratio.

NOX: noxious TRYCATS with neurotoxic, excitotoxic, inflammatory and oxidative properties, PRO: more protective TRYCATs.

NOX/PRO: $\mathrm{z}$ scores $\mathrm{PA}+3 \mathrm{HK}+\mathrm{XA}+\mathrm{QA}-\mathrm{z}$ scores $\mathrm{KA}+\mathrm{AA}$

associated with PANSS + and IgA responses to PA (positively) and AA (negatively) and IgM responses to $3 \mathrm{HK}$ (negatively) and KA (positively) being associated with PANSS - symptoms.

\section{Discussion}

The main finding of this study is that TRYCATs simultaneously explain part of the variance in depressive, anxiety and hypomanic symptom dimensions, as well as positive and negative symptoms in schizophrenia. This is a first study to show significant associations between affective symptom dimensions in schizophrenia and peripheral IgA and IgM responses directed against TRYCATs, including the ratio of noxious/more protective TRYCATs and the IgA - IgM responses to TRYCATs and noxious/protective TRYCAT ratio. The latter ratio offers an index for the neurotoxic + excitotoxic + cytotoxic + pro-inflammatory + pro-nitro-oxidative (i.e. QA, PA, XA and 3HK) versus the more neuro-protective TRYCATs, AA and KA (Kanchanatawan et al., 2017a, 2017b). $\Delta \operatorname{IgA}$ - IgM values indicate the ratio of IgA to IgM responses and, therefore, the net activation state of TRYCATs (including noxious/protective ratio), with IgA values reflecting TRYCAT activity levels and IgM values (probably) indicating regulatory activity (Kanchanatawan et al., 2017b). Regulatory activity is part of the "compensatory (anti)inflammatory reflex system" (CIRS) (Maes et al., 2012; Kanchanatawan et al., 2017b), which is mounted during acute and chronic immune-inflammatory responses and is characterized by reflex counter-regulation with negative immune-regulatory and antiinflammatory effects, which tends to attenuate an overzealous inflammatory response (Maes et al., 2012). Natural IgM isotype mediated responses are a major component of the CIRS (Schwartz-Albiez et al., 2009; Stahl and Sibrowski, 2003; Maes et al., 2006, 2013).
The current study has identified the TRYCAT patterns that could be more closely associated with specific symptom dimensions of schizophrenia (see Fig. 1). Notably, all five dimensions were significantly associated with IgA responses to PA, noxious/protective ratio (except positive symptoms) and/or XA (except positive and depressive symptoms), suggesting that increased activity of noxious TRYCATs may drive different domains of schizophrenia-related psychopathology. Importantly, all four noxious TRYCATS (namely QA, XA, PA and 3HK) have neurotoxic effects (Kanchanatawan et al., 2017a, 2017b), while three of these show excitotoxic effects (namely QA, 3HK and XA). QA, 3HK and PA additionally activate oxidative pathways, while PA and QA activate different aspects of nitro-oxidative, nitrosative and immuneinflammatory pathways (Bosco et al., 2000; Braidy et al., 2009; Kanchanatawan et al., 2017a, 2017b; Maes et al., 2007, 2011b; Morris et al., 2016). AA and KA, on the other hand, display antioxidant and negative immune regulatory effects and thus lowered levels of these TRYCATs may increase vulnerability to noxious effects of the other TRYCATs measured here. Importantly, plasma levels of noxious TRYCATs, including QA, 3HK and kynurenine, partly determine brain levels of noxious TYCATS, such as QA (Kita et al., 2002), indicating that changes in their peripheral levels may have consequences for central neuro-immune and neuroprogressive processes, including disrupting neuronal circuits and impairing neurogenesis, neuroplasticity and neuronal functioning (Morris et al., 2016). As such, increased levels of noxious TRYCATs and lowered levels of protective TRYCATs may contribute to overall psychopathology, including negative and positive symptoms of schizophrenia (Davis et al., 2014), negative symptoms and deficit schizophrenia (Kanchanatawan et al., 2017a), depressive symptoms (Maes et al., 2011b), hypomanic symptoms (Berk et al., 2011) and anxiety symptoms (Perna et al., 2016). 
Table 5

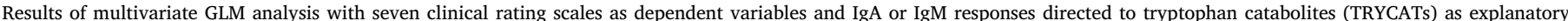
variables.

\begin{tabular}{|c|c|c|c|c|c|c|}
\hline Type test & Dependent variables & Explanatory variables & $\mathrm{F}$ & df & $\mathrm{p}$ & Partial eta squared \\
\hline \multirow[t]{3}{*}{ Multivariate $\neq 1$} & \multirow{3}{*}{$\begin{array}{l}\text { HDRSd, HDRSps, HAMAa, HAMAps, } \\
\text { YMRS, PANSS +, PANSS - }\end{array}$} & IgA PA & 4.65 & $7 / 106$ & $<0.001$ & 0.235 \\
\hline & & IgA AA & 2.33 & $7 / 106$ & 0.030 & 0.133 \\
\hline & & IgM NOX/PRO & 2.92 & $7 / 106$ & 0.008 & 0.162 \\
\hline \multirow[t]{13}{*}{ Between-subject effects } & \multirow[t]{2}{*}{ HDRSps } & $\operatorname{IgA} \mathrm{PA}(+)$ & 17.53 & $1 / 112$ & $<0.001$ & 0.135 \\
\hline & & $\operatorname{IgA}$ AA $(-)$ & 13.74 & $1 / 112$ & $<0.001$ & 0.109 \\
\hline & HAMAa & $\operatorname{IgA} \mathrm{PA}(+)$ & 7.81 & $1 / 112$ & 0.006 & 0.065 \\
\hline & \multirow{3}{*}{ HAMAps } & $\operatorname{IgA} \mathrm{AA}(-)$ & 4.15 & $1 / 112$ & 0.044 & 0.036 \\
\hline & & $\operatorname{IgA} \mathrm{PA}(+)$ & 9.74 & $1 / 112$ & 0.002 & 0.080 \\
\hline & & $\operatorname{IgA} \mathrm{AA}(-)$ & 5.16 & $1 / 112$ & 0.025 & 0.044 \\
\hline & YMRS & $\operatorname{IgA} \mathrm{PA}(+)$ & 16.17 & $1 / 112$ & $<0.001$ & 0.126 \\
\hline & PANSS + & $\operatorname{IgA}$ AA $(-)$ & 4.67 & $1 / 112$ & 0.033 & 0.040 \\
\hline & \multirow[t]{5}{*}{ PANSS - } & $\operatorname{IgA} \mathrm{PA}(+)$ & 9.31 & $1 / 112$ & 0.003 & 0.077 \\
\hline & & $\operatorname{IgA} \mathrm{AA}(-)$ & 7.69 & $1 / 112$ & 0.007 & 0.064 \\
\hline & & $\operatorname{IgA} \mathrm{PA}(+)$ & 15.76 & $1 / 112$ & $<0.001$ & 0.123 \\
\hline & & $\operatorname{IgA}$ AA $(-)$ & 6.02 & $1 / 112$ & 0.016 & 0.051 \\
\hline & & IgM NOX/PRO (-) & 5.80 & $1 / 112$ & 0.018 & 0.049 \\
\hline \multirow[t]{2}{*}{ Multivariate $\neq 2$} & \multirow{2}{*}{$\begin{array}{l}\text { HDRSd, HDRSps, HAMAa, HAMAps, } \\
\text { YMRS, PANSS +, PANSS - }\end{array}$} & $\Delta 3 \mathrm{HK}$ & 2.66 & $7 / 107$ & 0.014 & 0.148 \\
\hline & & $\Delta \mathrm{QA}$ & 2.11 & $7 / 107$ & 0.049 & 0.121 \\
\hline \multirow[t]{7}{*}{ Between-subject effects } & HDRSd & $\Delta 3 \mathrm{HK}(+)$ & 9.64 & $1 / 113$ & 0.002 & 0.079 \\
\hline & \multirow[t]{2}{*}{ HDRSps } & $\Delta 3 \mathrm{HK}(+)$ & 16.91 & $1 / 113$ & $<0.001$ & 0.130 \\
\hline & & $\Delta \mathrm{QA}(-)$ & 8.09 & $1 / 113$ & 0.005 & 0.067 \\
\hline & HAMAa & $\Delta 3 \mathrm{HK}(+)$ & 5.40 & $1 / 113$ & 0.022 & 0.046 \\
\hline & HAMAps & $\Delta 3 \mathrm{HK}(+)$ & 6.42 & $1 / 113$ & 0.013 & 0.054 \\
\hline & PANSS + & $\Delta \mathrm{QA}(-)$ & 4.71 & $1 / 113$ & 0.031 & 0.040 \\
\hline & PANSS - & $\Delta 3 \mathrm{HK}(+)$ & 5.52 & $1 / 113$ & 0.021 & 0.047 \\
\hline
\end{tabular}

HDRS: Hamilton Depression Rating Scale; HAMA: Hamilton Anxiety Rating Scale; YMRS: Young Mania Rating Scale.

HDRSd: an index of "pure" depressive symptoms computed as sum of item 1 (depressed mood) + item 2 (feelings of guilt) + item 3 (suicide).

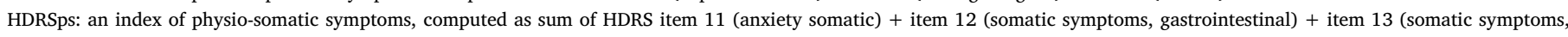
general) + item 14 (genital symptoms) + item 15 (hypochondriasis).

HAMAa: an index of "pure" anxiety symptoms computed as sum of items 1 (anxious mood) + item 2 (tension) + item 3 (fears) + item 14 (anxious behavior).

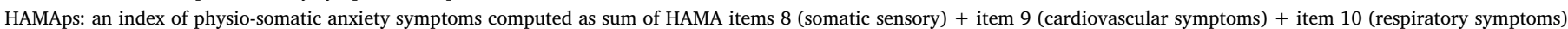

+ item 11 (gastrointestinal symptoms) + item 12 (genitourinary symptoms) + item 13 (autonomic symptoms).

PANSS + : Positive and Negative Syndrome Scale, sum of the positive symptom subscale.

PANSS - : Positive and Negative Syndrome Scale, sum of the negative symptom subscale.

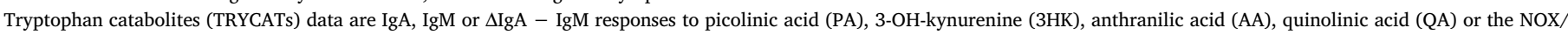
PRO ratio.

NOX: noxious TRYCATS with neurotoxic, excitotoxic, inflammatory and oxidative properties, PRO: more protective TRYCATs.

NOX/PRO: $\mathrm{z}$ scores PA + 3HK + XA (xanthurenic acid) + QA - z scores KA (kynurenic acid) + AA.

Previously, some reports showed significant associations between severity of affective rating scores and lowered plasma tryptophan coupled with increased levels of the noxious TRYCAT kynurenine (Maes et al., 2011b). For example, in the puerperium, mild increases in depression and anxiety scores, reminiscent of postnatal blues, are significantly associated with both lower tryptophan and increased kynurenine (Maes et al., 2001, 2002). During interferon- $\alpha$-based immunotherapy, the development of depressive symptoms is significantly associated with lower tryptophan and increased kynurenine levels (Bonaccorso et al., 2000, 2002; Machado et al., 2017). In HIVpositive patients, there is a significant correlation between severity of depression and both lower plasma tryptophan and increased kynurenine/tryptophan ratio (reflecting IDO activity) (Martinez et al., 2014). Hoes (1979) observed significant positive correlations between anxiety and XA concentrations following loading with $5 \mathrm{~g}$ L-tryptophan. Nevertheless, our findings in schizophrenia are difficult to compare with previous findings because in the current study participants with current and life-time diagnoses of major depression, dysthymic disorder, bipolar disorder, schizo-affective disorder and anxiety disorders were excluded. In addition, Table 1 shows that the mean HDRS, HAMA and YMRS scores monitored in our schizophrenia patients are lower than values obtained in acute major depression, severe anxiety disorders or acute mania. Moreover, in the current study we measured IgA/IgM responses to TRYCATs, whereas previous studies examined TRYCAT levels in plasma, cerebrospinal fluid and the brain. The measurement of plasma IgA/IgM levels responses to conjugated TRYCATs is probably a more adequate method than measuring their peripheral concentrations because assaying IgA responses indicates how the immune system perceives TRYCAT pathway activity, while measuring IgM responses to TRYCATs indicates self-regulatory activity, which tends to restrain overactivation of this pathway (Kanchanatawan et al., 2017b). Moreover, assays of peripheral IgA responses to TRYCATs may provide a window to pathophysiological events in the brain as plasma levels of TRYCATs partly determine brain concentrations (Kita et al., 2002) and IgA + plasma cells are present in the brain with intrathecal IgA being synthesized in neuroinflammatory disorders, including multiple sclerosis, and central nervous system infections (Bonnan, 2016). Interestingly, increased plasma IgA responses measured here may have a mucosal origin related to gut permeability (Roomruangwong et al., 2017a). Previous work, in both pregnant and non-pregnant women, shows that IgA responses to TRYCATs were significantly and positively related to IgA/IgM responses to antigens and LPS of gram-negative commensal bacteria (Roomruangwong et al., 2017a), whilst it is known that gut-derived inflammation following gluten sensitivity (as measured with anti-gliadin IgG autoantibodies) could contribute to TRYCAT pathway activation (as measured with the kynurenine/tryptophan ratio) in schizophrenia (Okusaga et al., 2016). It is also of note that alterations in gut microbiota and permeability are associated with changes in the activity of a number of brain regions, including the amygdala (Fernandez-Real et al., 2015), which is a brain nuclei that is classically linked to mood/affective regulation, including in schizophrenia (Anderson, 2011). 
Table 6

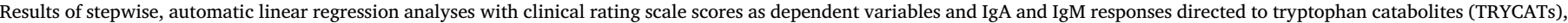
education, age and sex as explanatory variables.

\begin{tabular}{|c|c|c|c|c|c|}
\hline Dependent variables & Explanatory variables & $\mathrm{R}^{2}(\%)$ & $\mathrm{F}$ & $\mathrm{df}$ & $\mathrm{p}$ \\
\hline HDRS & $\begin{array}{l}\text { IgA PA }(\mathrm{t}=+4.01, p<0.001) \\
\text { IgA 3HK }(\mathrm{t}=+3.13, p=0.002) \\
\text { IgA AA }(t=-5.17, p<0.001) \\
\text { IgM 3HK }(t=-2.07, p=0.040) \\
\text { Education }(t=-3.76, p<0.001)\end{array}$ & 34.7 & 12.12 & $5 / 114$ & $<0.001$ \\
\hline HDRSps & $\begin{array}{l}\text { IgA PA }(\mathrm{t}=+3.51, p=0.001) \\
\text { IgA 3HK }(\mathrm{t}=+2.46, p=0.016) \\
\text { IgA AA }(t=-4.52, p<0.001) \\
\text { Education }(t=-2.72, p=0.008)\end{array}$ & $23.6 \%$ & 8.90 & $4 / 115$ & $<0.001$ \\
\hline HAMA & $\begin{array}{l}\text { IgA PA }(\mathrm{t}=+3.45, p=0.001) \\
\text { IgA AA }(t=-2.80, p=0.006) \\
\text { Education }(t=-1.94, p=0.055)\end{array}$ & $13.6 \%$ & 6.10 & $3 / 116$ & 0.001 \\
\hline HAMAa & $\begin{array}{l}\text { IgA PA }(t=+3.45, p=0.001) \\
\text { IgA QA }(t=-2.67, p=0.012)\end{array}$ & $9.4 \%$ & 6.06 & $2 / 117$ & 0.003 \\
\hline HAMAps & $\begin{array}{l}\text { IgA XA }(\mathrm{t}=+3.87, p<0.001) \\
\text { IgA AA }(t=-3.04, p=0.003) \\
\text { Education }(t=-2.50, p=0.014)\end{array}$ & $15.8 \%$ & 7.24 & $3 / 116$ & $<0.001$ \\
\hline YMRS & $\begin{array}{l}\text { IgA PA }(\mathrm{t}=+4.60, p<0.001) \\
\text { IgA QA }(t=-2.81, p=0.006) \\
\text { IgM AA }(t=-3.96, p<0.001) \\
\text { IgM QA }(\mathrm{t}=+4.80, p<0.001)\end{array}$ & $31.3 \%$ & 13.12 & $4 / 115$ & $<0.001$ \\
\hline PANSS + & $\begin{array}{l}\text { IgM QA }(\mathrm{t}=+3.80, p<0.001) \\
\text { IgM 3HK }(t=-2.82, p=0.006) \\
\text { Education }(t=-2.34, p=0.021) \\
\text { Sex }(t=-3.55, p=0.001)\end{array}$ & $22.6 \%$ & 8.33 & $4 / 114$ & $<0.001$ \\
\hline PANSS - & $\begin{array}{l}\text { IgA PA }(\mathrm{t}=+3.23, p=0.002) \\
\text { IgA AA }(t=-2.09, p=0.039) \\
\text { IgM 3HK }(t=-3.92, p<0.001) \\
\text { IgM KA }(\mathrm{t}=+3.19, p=0.001) \\
\text { Education }(t=-3.29, p=0.001) \\
\text { Sex }(t=-2.05, p=0.043)\end{array}$ & $36.1 \%$ & 10.54 & $6 / 112$ & $<0.001$ \\
\hline
\end{tabular}

HDRS: Hamilton Depression Rating Scale; HAMA: Hamilton Anxiety Rating Scale; YMRS: Young Mania Rating Scale.

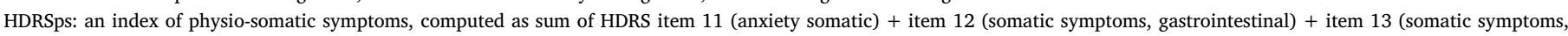
general) + item 14 (genital symptoms) + item 15 (hypochondriasis).

HAMAa: an index of "pure" anxiety symptoms computed as sum of items 1 (anxious mood) + item 2 (tension) + item 3 (fears) + item 14 (anxious behavior).

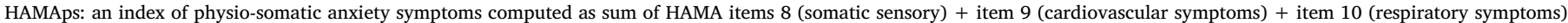

+ item 11 (gastrointestinal symptoms) + item 12 (genitourinary symptoms) + item 13 (autonomic symptoms).

PANSS + : Positive and Negative Syndrome Scale, sum of the positive symptom subscale.

PANSS - : Positive and Negative Syndrome Scale, sum of the negative symptom subscale.

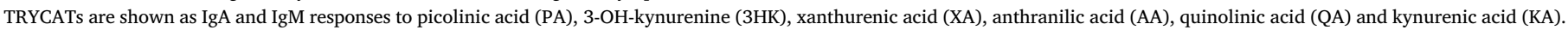

Overall, the findings of this paper support the theory that patients with schizophrenia are primed to develop depression through activation of immune-inflammatory and oxidative stress pathways, including the TRYCAT pathway (Anderson et al., 2013). Moreover, the current results suggest that patients with schizophrenia may also be primed to develop anxiety and hypomanic symptoms, which could at least in part be explained by aberrations in the same pathway. Affective symptoms in schizophrenia have been suggested to be secondary to positive symptoms rather than negative symptoms, although results are mixed (Emsley et al., 1999; Kirschner et al., 2016). The current study, however, shows that all five measured symptom dimensions of schizophrenia are associated with TRYCAT pathway alterations, suggesting that TRYCATs and their antecedents (pro-inflammatory cytokines, stress and nitro-oxidative processes) as well as their consequences to neuronal-glia functioning, are important mediators of an array of processes underpinning the pathophysiology of schizophrenia. This would suggest that affective symptoms in schizophrenia are not necessarily secondary to negative or positive symptoms but rather may have a common underlying pathophysiology.

The second major finding of this study indicates that the affective symptom dimensions and positive and negative symptoms of schizophrenia are associated with changes in IgM-mediated immune responses to TRYCATS. Firstly, increased IgM responses to QA were associated with all five symptom dimensions. QA is one of the most potent neurotoxic TRYCATs, with potent excitotoxic, inflammatory and nitro- oxidative properties, thereby likely leading to mitochondrial dysfunction and the induction of apoptotic or cell death pathways (LugoHuitrón et al., 2013; Maes et al., 2007; Morris et al., 2016). Increasing IgM responses to QA are associated with overall pathophysiology, which could indicate increased counter-regulation thereby attenuating the neurotoxic effects of QA. Lowered IgM responses to 3HK in association with anxiety, depression and negative symptoms would indicate a lowered negative feedback on $3 \mathrm{HK}$ production, thereby driving the significant correlations between $\triangle 3 \mathrm{HK}$ values and depression, anxiety and negative symptoms in schizophrenia patients. $3 \mathrm{HK}$ and AA can also have direct impacts on mitochondrial functioning (Baran et al., 2016), including in interaction with other factors linked to TRYCATs regulation and effects, including the alpha 7 nicotinic receptor, aryl hydrocarbon receptor and melatonergic pathways (Anderson and Maes, 2016, 2017). As such, the data presented here will be highly correlated with wider biochemical changes that are relevant to basic cellular functioning. Interestingly, major depression is accompanied by increased IgM responses to various oxidatively modified membrane components, including MDA, azelaic acid and oleic acid indicating that a natural autoimmune responses in mounted against oxidative damaged cells (Maes et al., 2006, 2013). Thus, it appears that natural IgM-mediated immune responses may be associated with major depression and depressive symptoms accompanying schizophrenia.

Importantly, negative symptoms, but not the four other symptom profiles, were significantly associated with lowered IgM responses to 


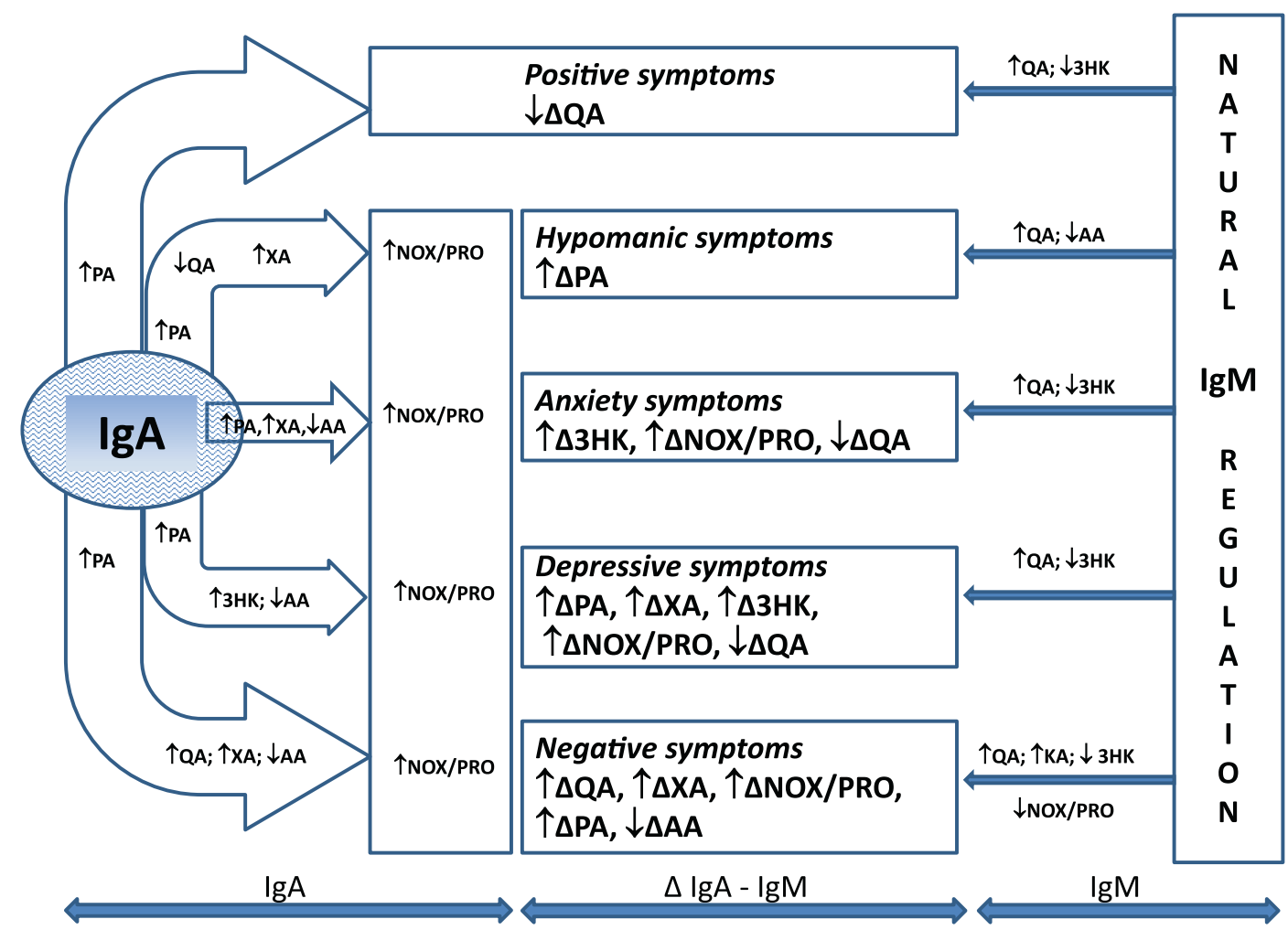

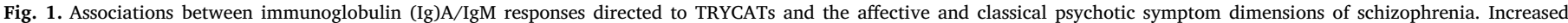

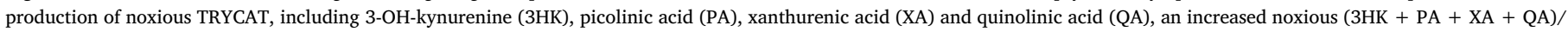

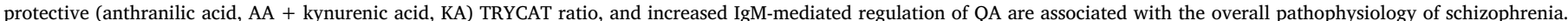

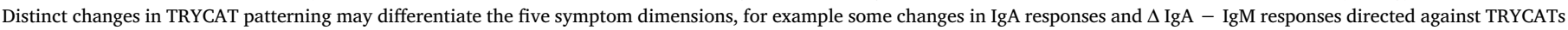
are more specific for depressive and negative ( $\triangle 3 \mathrm{HK}, \Delta \mathrm{XA}$ ), hypomanic (lower IgM to AA) and anxiety (lower IgA to AA) symptoms.

the noxious/protective ratio, suggesting that lowered regulation of noxious TRYCATs, and thus increased activity levels, are significantly associated with negative symptoms. Also, these IgM results may be relevant to brain function as a) IgM regulation of the peripheral TRYCAT pathway may, in part, determine brain TRYCAT levels, b) IgM antibodies may be present in the brain following increased leakiness of the blood-brain-barrier, and c) IgM antibodies may be produced by plasma cells in the brain (Walsh et al., 1985).

Interestingly, we also detected that TRYCATs patterning may differentiate between the different aspects of depressive presentations, including "pure depressive" and "physio-somatic" symptoms. Increased IgA and IgM responses to noxious TRYCATs are associated with the physio-somatic symptoms of the HDRS, whereas there were no significant associations with "pure depressive" symptoms, but only modest associations with the responses. These results are in agreement with previous research in pregnant women, where increased IgA responses to noxious TRYCATs are associated with physio-somatic symptoms at the end of term (including fatigue, dyspepsia, muscle pain, headache, and gastro-intestinal symptoms) and not with perinatal depression (Roomruangwong et al., 2017b). The results of the current study are also in agreement with those of a prior study showing that in depression lowered plasma tryptophan and increased kunurenine levels are associated with somatization rather than with depression per se and that these changes in the TRYCAT pathway are a hallmark for somatization (Maes et al., 2011a; Maes and Rief, 2012).

All in all, while increased production of noxious TRYCAT and increased IgM-mediated regulation of QA are associated with the overall pathophysiology of schizophrenia, other changes in TRYCAT patterning differentiate the five symptom dimensions (see Fig. 1). For example, some changes in IgA responses and $\Delta$ responses directed against TRYCATs are specific for depressive and negative $(\Delta 3 \mathrm{HK}, \triangle \mathrm{XA})$, hypomanic (lower IgM to AA) and anxiety (lower IgA to AA) symptoms.
A first limitation of the current study is its cross-sectional design, which prevents causal modelling. Therefore, future research should prospectively investigate the onset of affective, negative and positive symptoms in relation to TRYCAT pathway patterning in a cohort of individuals at high-risk of developing psychoses. A second limitation is that we measured only six TRYCATs, omitting others such as kynurenine. The data would also be greatly enhanced by measures of factors intimately linked to the TRYCATs pathway, including cytokines, stress and the gut microbiome, as well as the serotonin and melatonergic pathways. It could be argued that we should have used a more specific instrument to measure depressive symptoms in schizophrenia, e.g. the Calgary Depression Scale for Schizophrenia (CDSS). However, a recent systematic review suggests that the HDRS can reliably assess depressive psychopathology in schizophrenia (Lako et al., 2012), while we found that the HDRS score is more significantly correlated with objective neurocognitive deficits than the CDSS (Kanchanatawan et al., 2017c).

In conclusion, alterations in TRYCAT pathway activity, along with its regulators and consequents, may contribute to the emergence of affective, anxiety and hypomanic symptoms, as well as negative and positive symptoms in schizophrenia, via both shared and distinct mechanisms.

\section{Conflict of interest}

The authors have no conflict of interest with any commercial or other association in connection with the submitted article.

\section{Author's contributions}

BK and MM designed the study. BK recruited patients and completed diagnostic interviews and rating scales measurements. SS performed TRYCAT measurements. MM carried out the statistical analyses. 
All authors contributed to interpretation of the data and writing of the manuscript.

\section{Acknowledgement}

This research has been supported by the Asahi Glass Foundation, Chulalongkorn University Centenary Academic Development Project.

\section{References}

Anderson, G., 2011. Neuronal-immune interactions in mediating stress effects in the etiology and course of schizophrenia: role of the amygdala in developmental co-ordination. Med. Hypotheses 76, 54-60.

Anderson, G., Maes, M., 2016. How immune-inflammatory processes link CNS and psychiatric disorders: classification and treatment implications. CNS Neurol. Disord. Drug Targets (Nov 22 [Epub ahead of print] PubMed PMID: 27875954).

Anderson, G., Maes, M., 2017. The interactions of tryptophan and its catabolites with melatonin and the alpha 7 nicotinic receptor in CNS and psychiatric disorders: role for the aryl hydrocarbon receptor and direct mitochondria regulation. Int. J. Tryptophan Res. 10, 1-8.

Anderson, G., Maes, M., Berk, M., 2013. Schizophrenia is primed for an increased expression of depression through activation of immuno-inflammatory, oxidative and nitrosative stress, and tryptophan catabolite pathways. Prog. NeuroPsychopharmacol. Biol. Psychiatry 42, 101-114.

Anderson, G., Berk, M., Maes, M., 2014. Biological phenotypes underpin the physio-somatic symptoms of somatization, depression, and chronic fatigue syndrome. Acta Psychiatr. Scand. 129, 83-97.

Anderson, G., Jacob, A., Bellivier, F., Geoffroy, P.A., 2016. Bipolar disorder: The role of the kynurenine and melatonergic pathways. Curr. Pharm. Des. 22, 987-1012.

Andreasen, N.C., Olsen, S., 1982. Negative v positive schizophrenia. Definition and validation. Arch. Gen. Psychiatry 39, 789-794.

Baran, H., Staniek, K., Bertignol-Spörr, M., Attam, M., Kronsteiner, C., Kepplinger, B., 2016. Effects of various kynurenine metabolites on respiratory parameters of rat brain, liver and heart mitochondria. Int. J. Tryptophan Res. 9, 17-29.

Barry, S., Clarke, G., Scully, P., Dinan, T.G., 2009. Kynurenine pathway in psychosis: evidence of increased tryptophan degradation. J. Psychopharmacol. 23, 287-294.

Bay-Richter, C., Linderholm, K.R., Lim, C.K., Samuelsson, M., Träskman-Bendz, L., Guillemin, G.J., Erhardt, S., Brundin, L., 2014. A role for inflammatory metabolites as modulators of the glutamate N-methyl-D-aspartate receptor in depression and suicidality. Brain Behav. Immun. 43, 110-117.

Berk, M., Kapczinski, F., Andreazza, A.C., Dean, O.M., Giorlando, F., Maes, M., Yücel, M., Gama, C.S., Dodd, S., Dean, B., Magalhães, P.V., Amminger, P., McGorry, P., Malhi, G.S., 2011. Pathways underlying neuroprogression in bipolar disorder: focus on inflammation, oxidative stress and neurotrophic factors. Neurosci. Biobehav. Rev. 35, 804-817.

Bonaccorso, S., Meltzer, H., Maes, M., 2000. Psychological and behavioural effects of interferons. Curr. Opin. Psychiatry 13, 673-677.

Bonaccorso, S., Marino, V., Puzella, A., Pasquini, M., Biondi, M., Artini, M., Almerighi, C., Verkerk, R., Meltzer, H., Maes, M., 2002. Increased depressive ratings in patients with hepatitis $C$ receiving interferon-alpha-based immunotherapy are related to interferon-alpha-induced changes in the serotonergic system. J. Clin. Psychopharmacol. 22, 86-90.

Bonnan, M., 2016. Intrathecal immunoglobulin synthesis in MS - A complete reappraisal. In: Gonzalez-Quevedo, A. (Ed.), Mental and Behavioural Disorders and Diseases of the Nervous System, Trending Topics in Multiple Sclerosis, http://dx.doi.org/10. 5772/63201. (Print ISBN 978-953-51-2656-0, Published: September 8, 2016).

Bosco, M.C., Rapisarda, A., Massazza, S., Melillo, G., Young, H., Varesio, L., 2000. The tryptophan catabolite picolinic acid selectively induces the chemokines macrophage inflammatory protein-1 alpha and -1 beta in macrophages. J. Immunol. 164 , 3283-3291.

Braidy, N., Grant, R., Adams, S., Brew, B.J., Guillemin, G.J., 2009. Mechanism for quinolinic acid cytotoxicity in human astrocytes and neurons. Neurotox. Res. 16, 77-86.

Davis, J., Moylan, S., Harvey, B.H., Maes, M., Berk, M., 2014. Neuroprogression in schizophrenia: Pathways underpinning clinical staging and therapeutic corollaries. Aust. N. Z. J. Psychiatry. 48, 512-529.

Davis, J., Eyre, H., Jacka, F.N., Dodd, S., Dean, O., McEwen, S., Debnath, M., McGrath, J., Maes, M., Amminger, P., McGorry, P.D., Pantelis, C., Berk, M., 2016. A review of vulnerability and risks for schizophrenia: beyond the two hit hypothesis. Neurosci. Biobehav. Rev. 65, 185-194.

Duleu, S., Mangas, A., Sevin, F., Veyret, B., Bessede, A., Geffard, M., 2010. Circulating antibodies to IDO/THO pathway metabolites in Alzheimer's disease. Int. J. Alzheimers Dis. 15, 2010 (pii: 501541).

Emsley, R.A., Oosthuizen, P.P., Joubert, A.F., Roberts, M.C., Stein, D.J., 1999. Depressive and anxiety symptoms in patients with schizophrenia and schizophreniform disorder. J. Clin. Psychiatry 60, 747-751.

Fazio, F., Lionetto, L., Curto, M., Iacovelli, L., Cavallari, M., Zappulla, C., Ulivieri, M., Napoletano, F., Capi, M., Corigliano, V., Scaccianoce, S., Caruso, A., Miele, J., De Fusco, A., Di Menna, L., Comparelli, A., De Carolis, A., Gradini, R., Nisticò, R., De Blasi, A., Girardi, P., Bruno, V., Battaglia, G., Nicoletti, F., Simmaco, M., 2015. Xanthurenic acid activates mGlu2/3 metabotropic glutamate receptors and is a potential trait marker for schizophrenia. Sci Rep 5, 17799.

Fernandez-Real, J.M., Serino, M., Blasco, G., Puig, J., Daunis-i-Estadella, J., Ricart, W., Burcelin, R., Fernández-Aranda, F., Portero-Otin, M., 2015. Gut microbiota interacts with brain microstructure and function. J. Clin. Endocrinol. Metab. 100, 4505-4513. Gabbay, V., Klein, R.G., Katz, Y., Mendoza, S., Guttman, L.E., Alonso, C.M., Babb, J.S., Hirsch, G.S., Liebes, L., 2010. The possible role of the kynurenine pathway in adolescent depression with melancholic features. J. Child Psychol. Psychiatry 51 935-943.

Goldsmith, D.R., Rapaport, M.H., Miller, B.J., 2016. A meta-analysis of blood cytokine network alterations in psychiatric patients: comparisons between schizophrenia, bipolar disorder and depression. Mol. Psychiatry 21, 1696-1709.

Hamilton, M., 1959. The assessment of anxiety states by rating. Br. J. Med. Psychol. 32, 50-55.

Hamilton, M., 1960. A rating scale for depression. J. Neurol. Neurosurg. Psychiatry 23, 56-62.

Heatherton, T.F., Kozlowski, L.T., Frecker, R.C., Fagerström, K.O., 1991. The Fagerström test for nicotine dependence: a revision of the Fagerström tolerance questionnaire. Br. J. Addict. 86, 1119-1127.

Hoes, M.J., 1979. The clinical significance of an elevated excretion of xanthurenic acid in psychiatric patients. Acta Psychiatr. Belg. 79, 638-646.

Kanchanatawan, B., Sirivichayakul, S., Ruxrungtham, K., Carvalho, A.F., Geffard, M., Ormstad, H., Anderson, G., Maes, M., 2017a. Deficit, but not nondeficit, schizophrenia is characterized by mucosa-associated activation of the tryptophan catabolite (TRYCAT) pathway with highly specific increases in IgA responses directed to picolinic, xanthurenic, and quinolinic acid. Mol. Neurobiol.. http://dx.doi.org/10.1007/ s12035-017-0417-6. ([Epub ahead of print] PubMed PMID: 28181189).

Kanchanatawan, B., Sirivichayakul, S., Ruxrungtham, K., Carvalho, A.F., Geffard, M., Anderson, G., Maes, M., 2017b. Deficit schizophrenia is characterized by defects in IgM-mediated responses to tryptophan catabolites (TRYCATs): a paradigm shift toward defects in natural self-regulatory immune responses coupled with mucosa-derived TRYCAT pathway activation. Mol. Neurobiol.. http://dx.doi.org/10.1007/ s12035-017-0465-y. (Mar 14 [Epub ahead of print] PubMed PMID: 28290151).

Kanchanatawan, B., Thika, S., Anderson, G., Galecki, P., Maes, M., 2017c. Affective symptoms in schizophrenia are strongly associated with neurocognitive deficits indicating disorders in executive functions, visual memory, attention and social cognition. Prog. Neuropsychopharmacol. Biol. Psychiatry. http://dx.doi.org/10.1016/j. pnpbp.2017.06.031. (pii: S0278-5846(17)30129-X Jun 27 [Epub ahead of print] PubMed PMID: 28666826).

Kay, S.R., Fiszbein, A., Opler, L.A., 1986. Negative symptom rating scale: limitations in psychometric and research methodology. Psychiatry Res. 19, 169-173.

Kim, J.H., Kim, S.Y., Lee, J., Oh, K.J., Kim, Y.B., Cho, Z.H., 2012. Evaluation of the factor structure of symptoms in patients with schizophrenia. Psychiatry Res. 197, 285-289.

Kirkpatrick, B., Buchanan, R.W., McKenney, P.D., Alphs, L.D., Carpenter Jr., W.T., 1989 The schedule for the deficit syndrome: an instrument for research in schizophrenia. Psychiatry Res. 30, 119-123.

Kirschner, M., Aleman, A., Kaiser, S., 2016. Secondary negative symptoms - a review of mechanisms, assessment and treatment. Schizophr. Res.. http://dx.doi.org/10.1016/ j.schres.2016.05.003. pii: S0920-9964(16)30224-9 (May 23 [Epub ahead of print] Review. PubMed PMID: 27230288).

Kita, T., Morrison, P.F., Heyes, M.P., Markey, S.P., 2002. Effects of systemic and central nervous system localized inflammation on the contributions of metabolic precursors to the L-kynurenine and quinolinic acid pools in brain. J. Neurochem. 82, 258-268.

Kittirathanapaiboon, P., Khamwongpin, M., 2005. The Validity of the Mini International Neuropsychiatric Interview (M.I.N.I.). Thai Version Suanprung Hospital, Department of Mental Health.

Krause, D., Weidinger, E., Dippel, C., Riedel, M., Schwarz, M.J., Müller, N., Myint, A.M., 2013. Impact of different antipsychotics on cytokines and tryptophan metabolites in stimulated cultures from patients with schizophrenia. Psychiatr. Danub. 25, 389-397.

Lako, I.M., Bruggeman, R., Knegtering, H., Wiersma, D., Schoevers, R.A., Slooff, C.J., Taxis, K., 2012. A systematic review of instruments to measure depressive symptoms in patients with schizophrenia. J. Affect. Disord. 140, 38-47.

Laugeray, A., Launay, J.M., Callebert, J., Surget, A., Belzung, C., Barone, P.R., 2011. Evidence for a key role of the peripheral kynurenine pathway in the modulation of anxiety- and depression-like behaviours in mice: focus on individual differences. Pharmacol. Biochem. Behav. 98, 161-168.

Lee, M., Jayathilake, K., Dai, J., Meltzer, H.Y., 2011. Decreased plasma tryptophan and tryptophan/large neutral amino acid ratio in patients with neuroleptic-resistant schizophrenia: relationship to plasma cortisol concentration. Psychiatry Res. 185, 328-333.

Lieberman, J.A., Jody, D., Alvir, M.J., Borenstein, M., Mayerhoff, D.I., Geisler, S., Szymanski, S., Gonzales, A., Bogerts, B., 1991. Negative symptoms in schizophrenia: relationship to positive symptoms and outcome. In: Marneros, A., Andreasen, N., Tsuang, M.T. (Eds.), Negative Versus Positive Schizophrenia. Springer-Verlag, Berlin Heidelberg, pp. 109-125.

Lindenmayer, J.P., Bernstein-Hyman, R., Grochowski, S., Bark, N., 1995. Psychopathology of schizophrenia: initial validation of a 5-factor model. Psychopathology 28, 22-31.

Linderholm, K.R., Skogh, E., Olsson, S.K., Dahl, M.L., Holtze, M., Engberg, G., Samuelsson, M., Erhardt, S., 2012. Increased levels of kynurenine and kynurenic acid in the CSF of patients with schizophrenia. Schizophr. Bull. 38, 426-432.

Lugo-Huitrón, R., Ugalde Muñiz, P., Pineda, B., Pedraza-Chaverrí, J., Ríos, C., Pérez-de la Cruz, V., 2013. Quinolinic acid: an endogenous neurotoxin with multiple targets. Oxidative Med. Cell. Longev. 2013, 104024.

Machado, M.O., Oriolo, G., Bortolato, B., Köhler, C.A., Maes, M., Solmi, M., Grande, I., Martín-Santos, R., Vieta, E., Carvalho, A.F., 2017. Biological mechanisms of depression following treatment with interferon for chronic hepatitis C: a critical systematic review. J. Affect. Disord. 209, 235-245.

Maes, M., Rief, W., 2012. Diagnostic classifications in depression and somatization should include biomarkers, such as disorders in the tryptophan catabolite (TRYCAT) 
pathway. Psychiatry Res. 196, 243-249.

Maes, M., Meltzer, H.Y., Scharpé, S., Bosmans, E., Suy, E., De Meester, I., Calabrese, J., Cosyns, P., 1993. Relationships between lower plasma L-tryptophan levels and immune-inflammatory variables in depression. Psychiatry Res. 49, 151-165.

Maes, M., Meltzer, H.Y., Bosmans, E., 1994. Immune-inflammatory markers in schizophrenia: comparison to normal controls and effects of clozapine. Acta Psychiatr. Scand. 89, 346-351.

Maes, M., Bosmans, E., Calabrese, J., Smith, R., Meltzer, H.Y., 1995. Interleukin-2 and interleukin-6 in schizophrenia and mania: effects of neuroleptics and mood stabilizers. J. Psychiatr. Res. 29, 141-152.

Maes, M., Ombelet, W., Verkerk, R., Bosmans, E., Scharpé, S., 2001. Effects of pregnancy and delivery on the availability of plasma tryptophan to the brain: relationships to delivery-induced immune activation and early post-partum anxiety and depression. Psychol. Med. 31, 847-858.

Maes, M., Verkerk, R., Bonaccorso, S., Ombelet, W., Bosmans, E., Scharpé, S., 2002. Depressive and anxiety symptoms in the early puerperium are related to increased degradation of tryptophan into kynurenine, a phenomenon which is related to immune activation. Life Sci. 71, 1837-1848.

Maes, M., Mihaylova, I., Leunis, J.C., 2006. Chronic fatigue syndrome is accompanied by an IgM-related immune response directed against neopitopes formed by oxidative or nitrosative damage to lipids and proteins. Neuro Endocrinol. Lett. 27, 615-621.

Maes, M., Mihaylova, I., Ruyter, M.D., Kubera, M., Bosmans, E., 2007. The immune effects of TRYCATs (tryptophan catabolites along the IDO pathway): relevance for depression - and other conditions characterized by tryptophan depletion induced by inflammation. Neuro Endocrinol. Lett. 28, 826-831.

Maes, M., Galecki, P., Verkerk, R., Rief, W., 2011a. Somatization, but not depression, is characterized by disorders in the tryptophan catabolite (TRYCAT) pathway, indicating increased indoleamine 2,3-dioxygenase and lowered kynurenine aminotransferase activity. Neuro Endocrinol. Lett. 32, 264-273.

Maes, M., Leonard, B.E., Myint, A.M., Kubera, M., Verkerk, R., 2011b. The new '5-HT' hypothesis of depression: cell-mediated immune activation induces indoleamine 2,3dioxygenase, which leads to lower plasma tryptophan and an increased synthesis of detrimental tryptophan catabolites (TRYCATs), both of which contribute to the onset of depression. Prog. Neuro-Psychopharmacol. Biol. Psychiatry 35, 702-721.

Maes, M., Berk, M., Goehler, L., Song, C., Anderson, G., Gałecki, P., Leonard, B., 2012. Depression and sickness behavior are Janus-faced responses to shared inflammatory pathways. BMC Med. 29, 10-66.

Maes, M., Kubera, M., Mihaylova, I., Geffard, M., Galecki, P., Leunis, J.C., Berk, M., 2013. Increased autoimmune responses against auto-epitopes modified by oxidative and nitrosative damage in depression: Implications for the pathways to chronic depression and neuroprogression. J. Affect. Disord. 149, 23-29.

Martinez, P., Tsai, A.C., Muzoora, C., Kembabazi, A., Weiser, S.D., Huang, Y., Haberer, J.E., Martin, J.N., Bangsberg, D.R., Hunt, P.W., 2014. Reversal of the Kynurenine pathway of tryptophan catabolism may improve depression in ART-treated HIV-infected Ugandans. J. Acquir. Immune Defic. Syndr. 65, 456-462.

Mellor, C.S., 1991. Methodological problems in identifying and measuring first-rank symptoms of schizophrenia. In: Marneros, A., Andreasen, N., Tsuang, M.T. (Eds.), Negative Versus Positive Schizophrenia. Springer-Verlag, Berlin Heidelberg, pp. 71-78.

Miller, C.L., Llenos, I.C., Dulay, J.R., Barillo, M.M., Yolken, R.H., Weis, S., 2004. Expression of the kynurenine pathway enzyme tryptophan 2,3-dioxygenase is increased in the frontal cortex of individuals with schizophrenia. Neurobiol. Dis. 15, 618-629.

Morris, G., Carvalho, A.F., Anderson, G., Galecki, P., Maes, M., 2016. The many neuroprogressive actions of tryptophan catabolites (TRYCATs) that may be associated with the pathophysiology of neuro-immune disorders. Curr. Pharm. Des. 22, 963-977.

Noto, C., Ota, V.K., Santoro, M.L., Ortiz, B.B., Rizzo, L.B., Higuchi, C.H., Cordeiro, Q., Belangero, S.I., Bressan, R.A., Gadelha, A., Maes, M., Brietzke, E., 2015a. Effects of depression on the cytokine profile in drug naïve first-episode psychosis. Schizophr.
Res. 164, 53-58.

Noto, C., Ota, V.K., Santoro, M.L., Gouvea, E.S., Silva, P.N., Spindola, L.M., Cordeiro, Q., Bressan, R.A., Gadelha, A., Brietzke, E., Belangero, S.I., Maes, M., 2016. Depression, cytokine, and cytokine by treatment interactions modulate gene expression in antipsychotic naïve first episode psychosis. Mol. Neurobiol.. http://dx.doi.org/10.1007/ s12035-015-9489-3. (Epub 2015 Oct 22. PubMed PMID: 26491028).

Okusaga, O., Fuchs, D., Reeves, G., Giegling, I., Hartmann, A.M., Konte, B., Friedl, M., Groer, M., Cook, T.B., Stearns-Yoder, K.A., Pandey, J.P., Kelly, D.L., Hoisington, A.J., Lowry, C.A., Eaton, W.W., Brenner, L.A., Rujescu, D., Postolache, T.T., 2016. Kynurenine and tryptophan levels in patients with schizophrenia with elevated ANTIGLIADIN immunoglobulin G antibodies. Psychosom. Med (Jun 29. [Epub ahead of print] PubMed PMID: 27359171).

Olsson, S.K., Sellgren, C., Engberg, G., Landén, M., Erhardt, S., 2012. Cerebrospinal fluid kynurenic acid is associated with manic and psychotic features in patients with bipolar I disorder. Bipolar Disord. 14, 719-726.

Perna, G., Iannone, G., Alciati, A., Caldirola, D., 2016. Are anxiety disorders associated with accelerated aging? A focus on neuroprogression. Neural Plast. 2016, 8457612.

Roomruangwong, C., Kanchanatawan, B., Sirivichayakul, S., Anderson, G., Carvalho, A.F., Duleu, S., Geffard, M., Maes, M., 2017a. IgA/IgM responses to Gram-negative bacteria are not associated with prenatal depression, but with physio-somatic symptoms and activation of the tryptophan catabolite pathway at the end of term and postnatal anxiety. CNS Neurol. Disord. Drug Targets. http://dx.doi.org/10.2174/

1871527316666170407145533. ([Epub ahead of print] PubMed PMID: 28403801).

Roomruangwong, C., Kanchanatawan, B., Sirivichayakul, S., Anderson, G., Carvalho, A.F., Duleu, S., Geffard, M., Maes, M., 2017b. IgA/IgM responses to tryptophan and tryptophan catabolites (TRYCATs) are differently associated with prenatal depression, physio-somatic symptoms at the end of term and premenstrual syndrome. Mol. Neurobiol. 54, 3038-3049.

Salazar, A., Gonzalez-Rivera, B.L., Redus, L., Parrott, J.M., O'Connor, J.C., 2012. Indoleamine 2,3-dioxygenase mediates anhedonia and anxiety-like behaviors caused by peripheral lipopolysaccharide immune challenge. Horm. Behav. 62, 202-209.

Schwarcz, R., Rassoulpour, A., Wu, H.Q., Medoff, D., Tamminga, C.A., Roberts, R.C., 2001. Increased cortical kynurenate content in schizophrenia. Biol. Psychiatry 50, 521-530.

Schwartz-Albiez, R., Monteiro, R.C., Rodriguez, M., Binder, C.J., Shoenfeld, Y., 2009. Natural antibodies, intravenous immunoglobulin and their role in autoimmunity, cancer and inflammation. Clin. Exp. Immunol. 158 (Suppl. 1), 43-50.

Schwieler, L., Larsson, M.K., Skogh, E., Kegel, M.E., Orhan, F., Abdelmoaty, S., Finn, A., Bhat, M., Samuelsson, M., Lundberg, K., Dahl, M.L., Sellgren, C., Schuppe-Koistinen, I., Svensson, C., Erhardt, S., Engberg, G., 2015. Increased levels of IL-6 in the cerebrospinal fluid of patients with chronic schizophrenia — significance for activation of the kynurenine pathway. J. Psychiatry Neurosci. 40, 126-133.

Smith, R.S., Maes, M., 1995. The macrophage-T-lymphocyte theory of schizophrenia: additional evidence. Med. Hypotheses 45, 135-141.

Stahl, D., Sibrowski, W., 2003. Regulation of the immune response by natural IgM: lessons from warm autoimmune hemolytic anemia. Curr. Pharm. Des. 9, 1871-1880.

Steiner, J., Bogerts, B., Walter, B., Gos, T., Bernstein, H.G., Myint, A.M., Oct 2012. Bridging the gap between the immune and glutamate hypotheses of schizophrenia and major depression: Potential role of glial NMDA receptor modulators and impaired blood-brain barrier integrity. World J. Biol. Psychiatry 13 (7), 482-492.

Van den Oord, E.J., Rujescu, D., Robles, J.R., Giegling, I., Birrell, C., Bukszár, J., Murrelle, L., Möller, H.J., Middleton, L., Muglia, P., 2006. Factor structure and external validity of the PANSS revisited. Schizophr. Res. 82, 213-223.

Walsh, M.J., Tourtellotte, W.W., Roman, J., Dreyer, W., 1985. Immunoglobulin G, A, and $\mathrm{M}-$ clonal restriction in multiple sclerosis cerebrospinal fluid and serum-analysis by two-dimensional electrophoresis. Clin. Immunol. Immunopathol. 35, 313-327.

Young, R.C., Biggs, J.T., Ziegler, V.E., Meyer, D.A., 1978. A rating scale for mania: reliability, validity and sensitivity. Br. J. Psychiatry 133, 429-435. 